\title{
Microstructural Aspects of Zircaloy Nodular Corrosion in Steam
}

D.F. Taylor

July 1999

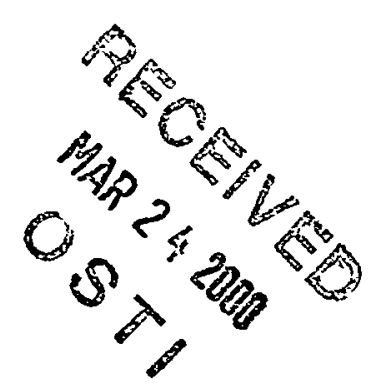

\section{NOTICE}

This report was prepared as an account of work sponsored by the United States Government. Neither the United States, nor the United States Department of Energy, nor any of their employees, nor any of their contractors, or their employees, makes any warranty, express or implied, or assumes any legal liability or responsibility for the accuracy, completeness or usefulness of any information, apparatus, product or process disclosed, or represents that its use would not infringe privately owned rights. 


\section{DISCLAIMER}

Portions of this document may be illegible in electronic image products. Images are produced from the best available original document. 


\title{
Microstructural Aspects of Zircaloy Nodular Corrosion in Steam
}

\author{
D.F. Taylor ${ }^{1}$ \\ GE Corporate Research and Development \\ Schenectady, NY 12301 \\ USA
}

\begin{abstract}
Zircaloy- 2 becomes susceptible to nodular corrosion in high-temperature, highpressure steam when the total solute concentration of the $\beta$-stabilizing alloying elements $\mathrm{Fe}, \mathrm{Ni}$ and $\mathrm{Cr}$ in the $\alpha$-zirconium matrix falls below a critical value $\mathrm{C}_{\mathrm{c}}$ that is characteristic of the test conditions. $\mathrm{C}_{\mathrm{c}}$ for typical commercial Zircaloy -2 in a $24 \mathrm{hr} / 510^{\circ} \mathrm{C} / 10.4 \mathrm{MPa}$ steam-test is the precipitate-free $\alpha$-matrix concentration in equilibrium with solutesaturated $\beta$ phase at about $840^{\circ} \mathrm{C}$, the corresponding critical temperature $T_{c}$. Thus, immunity to nodular corrosion is a metastable condition for $\alpha$-Zircaloy that requires fast cooling from above $T_{c}$ to achieve adequate solute concentration throughout the matrix. Annealing Zircaloy at any temperature below $T_{\mathfrak{c}}$ for a sufficiently long time makes it susceptible to nodular corrosion. In the $(\alpha+\chi)$ phase field, where $\chi$ collectively designates the $\mathrm{Fe}-, \mathrm{Cr}-$, and $\mathrm{Ni}$-containing precipitate phases, lowering the solute concentration to less than $\mathrm{C}_{\mathrm{c}}$ by Ostwald ripening can require many hundreds of hours. Above about $825^{\circ} \mathrm{C}$, the temperature of the $(\alpha+\chi) /(\alpha+\beta+\chi)$ transus, solute-saturated $\beta$ phase surrounds each precipitate and a strong "inverse" activity gradient promotes equilibration with the much lower solute concentration in the $\alpha$ matrix. Sensitization to nodular corrosion occurs most rapidly at about $835^{\circ} \mathrm{C}$ between the $(\alpha+\chi) /(\alpha+\beta+\chi)$ transus and $T_{c}$. Annealing Zircaloy at temperatures above $T_{c}$ for a sufficiently long time will raise the solute concentration above $\mathrm{C}_{\mathrm{c}}$ and, with rapid cooling, heal any degree of susceptibility. Annealing within the "protective coarsening window" between $T_{c}$ and about $850^{\circ} \mathrm{C}$, the temperature of the $(\alpha+\beta+\chi) /(\alpha+\beta)$ transus, achieves rapid precipitate growth in a matrix immune to nodular corrosion.
\end{abstract}

PACS: 81.05.Bx; 81.30.Mh; 81.40.Ef; 81.65.Mq

Key Words: Zircaloy; nodular corrosion; nuclear fuel cladding; BWR

\footnotetext{
' Present address: Lockheed Martin Corporation. P.O Box 1072-089. Schenectady. NY 12301. USA. E-mail: taylordf@usa.net
} 


\section{INTRODUCTION}

Slowing the acceleration of uniform corrosion on Zircaloy-2 fuel cladding in a boiling-water nuclear reactor (BWR) at high burn-up requires lower alloying-element solute concentrations, and hence, larger precipitates to resist dissolution by the neutron flux [1]. Manufacturing practices in recent years have produced uniform distributions of very fine precipitates to eliminate the nucleation of nodules early in life. To determine whether eliminating both nodular corrosion and excessive uniform corrosion might be mutually exclusive goals, it was necessary to examine the nature of the relationship between the precipitate distribution and nodular corrosion susceptibility.

Laboratory experiments and a detailed analysis of the Zircaloy literature led to the conclusion in a previous paper [2] that for a given oxidizing environment, there should be a critical minimum concentration of alloying elements that, when available to any site at the alloy/oxide interface, will prevent nodular corrosion. Kruger et al. [3] subsequently measured the concentrations of solute $\mathrm{Cr}, \mathrm{Fe}$ and $\mathrm{Ni}$ in the metal matrix of $\alpha$-Zircaloy-2 by atom-probe microchemical analysis, and compared those values with results from nodular-corrosion susceptibility tests in high-temperature, high-pressure steam. They found that an increase in matrix solute content, without a significant change in mean precipitate diameter, could cause a significant increase in resistance to nodular corrosion. Unfortunately, the precision of this very difficult technique was insufficient to establish the actual matrix composition with any certainty. Previously, Wadman and Andren [4] had reported similar atom-probe analyses of Zircaloy- 4 and concluded that $\beta$-quenching left the highest solute concentrations. Contrary to expectations, Kruger et al. measured lower values after $\beta$-quenching Zircaloy- 2 than after high- $\alpha$ annealing, and attributed the superior nodular-corrosion resistance from the former to direct oxidation of tiny precipitates. Both groups found nominal agreement with the solubility limits of Charquet et al. [5].

There remain controversies as to the physical mechanism of nodule formation, the nature of any electrochemical contributions from the precipitates, and the exact role of the protective alloying elements [6-12], but these questions are not at issue here. If local alloying-element concentrations control nodular corrosion susceptibility, the interdependence between precipitate distributions (spatial and size) and solute concentrations holds the key to optimizing corrosion properties. Gros and Wadier [13] described this relationship for $\alpha$-Zircaloy using the mathematics of Ostwald ripening. They developed and tested an expression to calculate the cumulative effect of isothermal anneals on mean precipitate size, and discussed its similarity to the empirical cumulative annealing parameter (CAP) that Garzarolli et al. $[14,15]$ derived from the earlier work of Steinberg et al. [16] for predicting corrosion susceptibility, but did not pursue the link between precipitates and corrosion here [13], or during their subsequent collaboration with Charquet et al. [5].

Cheng and Adamson [17] reported complete immunity to nodular corrosion in steam after heat treating one particular specimen of "susceptible" Zircaloy- 2 at $760^{\circ} \mathrm{C}$, 
high in the $\alpha$ phase field, but otherwise achieved only a reduction in nodule density. The author could neither reproduce experimentally, nor find additional evidence in the literature for, complete high- $\alpha$ healing. This implies that annealing in the $\alpha$ phase field cannot raise a lesser steady-state matrix solute concentration above the critical value. The Gros-Wadier steady-state Ostwald ripening model $[5,13]$ then leads to the conclusion that the immunity of $\alpha$-Zircaloy to nodular corrosion in steam requires a precipitate distribution fine enough for a mean alloying-element solute concentration greater than the critical value $C_{c}$ at the temperature of the final anneal.

This corrosion-model derivative of steady-state ripening predicts the global observations of Zircaloy's improvement in nodular-corrosion resistance with faster $\beta$ quench rates, and its increasing susceptibility to nodular corrosion with thermal aging in the $\alpha$ phase field [18-20]. The model is not consistent with the immunity to nodular corrosion that can accompany relatively coarse precipitate distributions, nor with observations of large, precipitate-free grains and sub-grains that are nodule-free in steam tests $[14,17,21]$.

Nodule-free $\alpha$-Zircaloy fuel cladding requires a slow transition from its initial state of metastable immunity toward inevitable steady-state susceptibility. If, after monotonic cooling into the $\alpha$ phase field, the matrix solute concentration exceeds the solubility of the smallest particle in the initial distribution, all precipitates coarsen. Ostwald ripening begins when the solute concentration falls below the maximum precipitate solubility and establishes a critical radius. This ripening parameter defines a mean solute concentration, and increases as the mean solute concentration decreases. The system finally reaches a steady state in which simple proportionality constants link the critical radius with precipitate size-distribution characteristics, such as the mode and mean, that are also increasing slowly with time. Available microstructural evidence suggests that the solute concentration can drop below $\mathrm{C}_{c}$ and sensitize the matrix during any phase of this effectively perpetual transient. For a dense, uniform spatial distribution of fine precipitates with an Ostwald mean-solute concentration initially greater than $\mathrm{C}_{c}$, the steady-state description of Ostwald ripening could be appropriate for predicting the changes in nodular-corrosion susceptibility that occur with thermal processing in the $\alpha$ phase field. Other immune materials would require analysis of the pre-steady-state transient [22]. In general, the microstructural transformations that take place during cooling from the $\beta$ or $(\alpha+\beta)$ phase fields into the $\alpha$ phase field establish either an initial degree of susceptibility, or a margin of immunity and starting point for subsequent sensitization. Precipitate solubilities ultimately control the matrix solute concentration, but a slow approach to steady-state would permit the partially independent manipulations of both protective solute concentration and precipitate-size distribution in the final product.

This paper first examines the mechanism by which slow cooling sensitizes one particular heat of Zircaloy- 2 to nodular corrosion in steam. It introduces the concept of a critical transition temperature, $T_{c}$, and estimates its value from kinetic data. Subsequent experiments demonstrate that $T_{c}$ is an important system characteristic, and independently 
confirm its value isothermally by extending the study to both the sensitization of Zircaloy-2 that is immune to nodular corrosion, and the healing of susceptible material. From these observations emerges a self-consistent, predictive model that offers guidelines for microstructural manipulation and explanations for memory, resistance to slow-cooling sensitization, and heat-to-heat variability. Collectively, the data from this study confirm previous literature values for the equilibrium temperatures of all phase transformations, and leave a clearer picture of the mechanisms by which thermo-mechanical processing alters nodular-corrosion susceptibility.

\section{EXPERIMENTAL}

Materials - Most experiments utilized "W2" tubing, GE Zircaloy-2 nuclear fuel cladding with a zirconium barrier liner from Tubing Lot 2054-06. The chemical composition of the Western Zirconium parent ingot, UX2700LB, was typical of current commercial Zircaloy2 , and included deliberate additions of $\mathrm{Si}$ and $\mathrm{C}: 1.27-1.34 \mathrm{Sn}, 0.15-0.18 \mathrm{Fe}, 0.09-0.11 \mathrm{Cr}$, $0.06-0.07 \mathrm{Ni}, 0.12-0.13 \mathrm{O}$ (all weight percent), with <40ppm N, 95-112ppm Si, 132$160 \mathrm{ppm}$ C. Specimens of Zircaloy-2 from several sources served to illustrate the variety of responses for different processing histories, and the text contains specific references to four of these: "T22," a cylindrical ingot from Teledyne Wah Chang Heat 223924Q, "ZNR," a triple re-melt of non-barrier tubeshell from WZ UX3020L that provided starting material for special alloys with nitrogen additions, "T1," barrier cladding from GE Lot 0002-01 (1990 - TWC 229136Q), and "T2," barrier cladding from GE Lot 7226-20 (1987 - TWC 224961Q). The compositions of these materials attested to the high industry-wide standards of quality control. All means lay within the W2 check-analysis ranges, and the chemistry specifications for $\mathrm{T} 1$ and $\mathrm{T} 2$ differed by no more than $5 \%$ in any category.

Annealing - The annealing furnace consisted of a $25 \mathrm{~mm}$-diameter quartz tube that passed vertically through a bank of radially symmetric heating elements. A Type-304 stainless steel hook suspended individual Zircaloy specimens in the middle of the hot zone. The tips of two $3 \mathrm{~mm}$ stainless steel thermocouple wells contacted the central external surface of the tubing segment or coupon, one on each side of the suspension hook, and held the control and monitor thermocouples in close proximity to the Zircaloy specimen. Researchgrade argon gas flowed at a constant rate of $60 \mathrm{cc} / \mathrm{min}$ through a getter of $\mathrm{Zr}-\mathrm{Ti}$ alloy turnings at $800^{\circ} \mathrm{C}$ before reaching the annealing zone of the quartz tube.

A programmable Research, Inc. Dimension Process Controller maintained isothermal annealing temperatures constant to within $\pm 0.3^{\circ} \mathrm{C}$, or changed the furnace temperature with time in a variety of patterns. In general, monotonic cooling through several temperature ranges at different rates followed heating at an average rate of about $40^{\circ} \mathrm{C} / \mathrm{min}$ to some maximum temperature. "Slow cooling" in these experiments was under program control at $0.005^{\circ} \mathrm{C} / \mathrm{s}$, only $18^{\circ} \mathrm{C} / \mathrm{hr}$. "Furnace cooling," the natural rate with the power off and the heating elements still in place, varied from about $0.7^{\circ} \mathrm{C} / \mathrm{s}$ to $0.6^{\circ} \mathrm{C} / \mathrm{s}$, very slow by most standards, but two orders of magnitude faster than "slow cooling." 
Opening the heating chamber and fan-cooling the quartz tube achieved a rate that typically started at $3^{\circ} \mathrm{C} / \mathrm{s}$, but had decreased to $1^{\circ} \mathrm{C} / \mathrm{s}$ by the time the temperature reached $500^{\circ} \mathrm{C}$. Changes from "slow cooling" to "furnace cooling" or "fan cooling" were abrupt and precise, but the transitions from "furnace cooling" to "slow cooling" required a gradual approach to avoid undershoot.

Etching and Corrosion Testing - Typical experiments consisted of etching the specimens with gentle agitation for $60 \mathrm{~s}$ in a solution of $10: 9: 1$ by volume water, $70 \%$ nitric acid, $50 \%$ hydrofluoric acid; then annealing, cutting a $3 \mathrm{~mm}$ archive section for metallography, reetching, and determining nodular corrosion susceptibility. This testing was by exposure to 10.4MPa steam at $510^{\circ} \mathrm{C}$ for $24 \mathrm{hr}$, laboratory conditions that yield a reasonable correlation with in-pile behavior $[23,24]$. A convection oven held the temperature throughout the interior of a one-liter Type 316 stainless steel autoclave constant to within $\pm 1^{\circ} \mathrm{C}$. A metering pump maintained the flow rate of $18 \mathrm{M} \Omega-\mathrm{cm}$ water at $20 \mathrm{cc} / \mathrm{min}$ after oxygen removal by nitrogen saturation under ambient conditions.

Optical Metallography - A final brief swab-etch with a solution of $4: 1: 1$ by volume glycerol, $70 \%$ nitric acid, 50\% hydrofluoric acid followed mounting, grinding to 4000 grit $\mathrm{SiC}$ paper, and etch-polishing in a mixture of $0.05 \mu \mathrm{m}$ silica slurry and the glycerol-base etch. Images in polarized-light at $100 \mathrm{X}$ and with differential interference contrast at $1000 \mathrm{X}$ complemented conventional bright-field images for most specimens.

\section{RESULTS}

\section{Scoping Experiments}

Slow Cooling from $\beta\left(1010^{\circ} \mathrm{C}\right)$, and $(\alpha+\beta)\left(950^{\circ} \mathrm{C}\right)$, to $\alpha\left(600^{\circ} \mathrm{C}\right)$ - Ranges of values appear in the literature for the principal transus temperatures of Zircaloy [25-27]. These choices for the initial investigation were arbitrary, but safely within all estimates of the boundaries for each phase field. The fine-grained, equiaxed- $\alpha(\mathrm{E} \alpha)$ test material developed a heavy coating of white nodular oxide after heating to $1010^{\circ} \mathrm{C}$, cooling linearly at $0.005^{\circ} \mathrm{C} / \mathrm{s}$ to $600^{\circ} \mathrm{C}$, fan cooling to ambient temperature, and testing in steam. The same procedure with a lower peak temperature of $950^{\circ} \mathrm{C}$ left the tubing specimens with a coating of black, shiny oxide, immune to nodular corrosion. Control specimens also were immune after heating to $1010^{\circ} \mathrm{C}$ and fan cooling; i.e., $\left[1010^{\circ} \mathrm{C} / \mathrm{Fan}-\mathrm{cool}\right]$ or $\mathrm{BF}$.

The Critical Interval $\left[830^{\circ} \mathrm{C}-800^{\circ} \mathrm{C}\right]$ - It was clear that slow-cooling sensitization with these parameters first required a complete transformation to $\beta$. Lowering the initial temperature and raising the final temperature of the slow-cooling portion of the heattreatment profile had little effect on steam test results until these limits were below $830^{\circ} \mathrm{C}$ and above $800^{\circ} \mathrm{C}$, respectively. Further narrowing of the slow-cooling interval started to decrease the severity of sensitization. This profile, $\left[1010^{\circ} \mathrm{C} /\right.$ furnace-cool to $830^{\circ} \mathrm{C} /$ 
Slow-cool to $800^{\circ} \mathrm{C} /$ Fan-cool to ambient], or $\beta S F$, became the standard for creating a reproducible state of severe sensitization throughout this study. The Widmanstatten structure in Figure 1 is typical for Zircaloy- 2 after cooling from the $\beta$ phase field at a moderate rate [28-30]. The $\beta S F$ heat treatment produced the microstructure in Figures 2(a) and 2(b).

Time and Sequence - Introducing a hold time after reaching the initial peak temperature eliminated the need to exceed the temperature of the $(\alpha+\beta) / \beta$ transus, $T_{\beta}$, for severe slowcooling sensitization. Starting with $\beta F$ tubing had the same effect. Thus, the heattreatment profiles $\left[950^{\circ} \mathrm{C}(2 \mathrm{hr}) /\right.$ furnace-cool to $830^{\circ} \mathrm{C} /$ Slow-cool to $800^{\circ} \mathrm{C} / \mathrm{Fan}$-cool to ambient] or $950(2) \mathrm{SF}$, and [BF; $950^{\circ} \mathrm{C} /$ furnace-cool to $830^{\circ} \mathrm{C} / \mathrm{Slow}-\mathrm{cool}$ to $800^{\circ} \mathrm{C} /$ Fan-cool to ambient], or $\beta F 950 S F$, were equally effective and equivalent to $\beta S F$ for generating heavy nodular corrosion in steam, while $950 \mathrm{SF}$ did not degrade the immunity of the production cladding. The BF950SF microstructure was the same as that for BSF (Figure 2). The 950(2)SF microstructure was equiaxed, but similar in other respects.

\section{Examination of Slow-Cooling Sensitization}

Transition in Susceptibility at the $(\alpha+\beta) / \beta$ Transus - The first step in resolving this complex picture was to confirm the role of the $(\alpha+\beta) / \beta$ phase transformation in $\beta S F$ sensitization. The array of steam-test specimens in Figure 3 shows that increasing the TSF "peaking profile" initial temperature $\mathrm{T}$ in steps of $5^{\circ} \mathrm{C}$ from $970^{\circ} \mathrm{C}$ to $1000^{\circ} \mathrm{C}$ caused a sequential transition from immunity at $980^{\circ} \mathrm{C}$, to tiny nodules and edge corrosion at $985^{\circ} \mathrm{C}$, to heavy nodular corrosion at $990^{\circ} \mathrm{C}$ and above. The corresponding micrographs showed progressive development of precipitate agglomerates like those in Figure 2 that coincided with the replacement of $\mathrm{E} \alpha$ grains by Widmanstatten platelets. The simple anneal/steam-test procedure provided a clear, visual indication that $T_{\beta}$ is about $985^{\circ} \mathrm{C}$ for this material.

Transition in Susceptibility during Slow Cooling - The slow-cooling portion of the BSF sensitizing profile bracketed most literature estimates for $T_{a}$, the temperature of the $(\alpha+\chi) /(\alpha+\beta+\chi)$ transus in Zircaloy-2. For convenience, $\chi$ represents all compositions of precipitates [25]. There are two principal intermetallic phases: hexagonal Laves phase $\mathrm{Zr}(\mathrm{Cr}, \mathrm{Fe})_{2}$ and tetragonal $\mathrm{Zr}_{2}(\mathrm{Ni}, \mathrm{Fe})$. Others exist, and there is little doubt that each alloying element contributes differently as matrix solute [7,11,12,15,27-29,31,32], but individual consideration is beyond the scope of this paper. The next step was to examine the attractively simple possibility that slow-cooling through this transformation caused the $\beta S F$ sensitization. Modifying the BSF profile to quantify the effects of both changing the pre-fan-cool termination temperature, and adding hold-time at that temperature, revealed the sensitizing mechanism. 
The new profiles retained the original slow-cooling rate of $0.005^{\circ} \mathrm{C} / \mathrm{s}$, but made the slow-cooling termination temperature a variable, $T_{i}$, and introduced a variable hold-time, t. For most experiments, the slow-cooling initiation temperature was $830^{\circ} \mathrm{C}$, but $T_{f}$ values above about $825^{\circ} \mathrm{C}$ required a higher setting to assure some slow cooling under program control prior to the period at constant $T_{i} .840^{\circ} \mathrm{C}$ was the arbitrary choice for the profile set-point in those experiments: $\left[1010^{\circ} \mathrm{C} /\right.$ furnace-cool to $830^{\circ} \mathrm{C}\left(\mathrm{T}_{\mathrm{t}}<825^{\circ} \mathrm{C}\right)$ or $840^{\circ} \mathrm{C}$ $\left(\mathrm{T}_{\mathrm{p}}>825^{\circ} \mathrm{C}\right.$ )/Slow-cool to $\mathrm{T}_{\mathrm{f}}$ (hold for $\mathrm{t} \mathrm{hr}$ ) / Fan-cool], or $B S-\mathrm{T}_{\mathrm{f}}(\mathrm{t}) \mathrm{F}$. $\mathrm{T}_{\mathrm{f}}$ changed in increments of $3^{\circ} \mathrm{C}$ for $\mathrm{t}=0$ (no hold-time before final cool), $2^{\circ} \mathrm{C}$ for $\mathrm{t}=2 \mathrm{hr}, 5 \mathrm{hr}$ and $18 \mathrm{hr}$, and $1^{\circ} \mathrm{C}$ for $\mathrm{t}=48 \mathrm{hr}$. Figure 4 is a photograph of the post-steam-test specimen matrix.

The transition between sheet oxide and immunity to nodular corrosion in steam always occurred over just a few degrees, and the transition temperature increased with increasing hold-time. The choice for each transition temperature was somewhat subjective, but it is clear that the approach to saturation was discontinuous: one value of about $825^{\circ} \mathrm{C}$ for the sequence $t=0 \mathrm{hr}, 2 \mathrm{hr}, 5 \mathrm{hr}$, and a higher value of about $840^{\circ} \mathrm{C}$ for the longer holdtimes of $18 \mathrm{hr}$ and $48 \mathrm{hr}$. Figures $2(\mathrm{~b})$ and 5 are representative of the photomicrographpairs that bracketed the dramatic change from susceptibility to immunity at transition temperatures below the discontinuity. Figure 5 typifies the microstructures of both susceptible and immune specimens from above the discontinuity. For each transition, a difference in $T_{f}$ of only $2^{\circ} \mathrm{C}$ separated susceptibility from immunity.

For $\mathrm{t}=0 \mathrm{hr}, 2 \mathrm{hr}, 5 \mathrm{hr}$, fan-cooling followed both the completion of the transformation to $\alpha$-Zircaloy and the subsequent nucleation and growth of small precipitates throughout the $\alpha$ matrix. Figure 5 shows a strikingly different microstructure. Here, fan-cooling preceded the final disappearance of $\beta$-Zircaloy, and most of the $\chi$ phase resided in those regions of prior- $\beta$ that surrounded the $\alpha$ grains. Clearly, the $\beta$-to- $\alpha$ phase transformation coincided with the onset of susceptibility. For longer hold times, the microstructures for $T_{f}$ values above and below the transition were indistinguishable. Both showed the gross segregation to diminishing $\beta$ that was characteristic of fan-cooling from temperatures above the final $\beta$-to- $\alpha$ phase transformation.

Optically identical micrographs for susceptible and immune materials like those in Figure 5 provide the most important supporting evidence for solute control of nodular corrosion. The only microstructural difference between highly susceptible and immune specimens was the difference in $\alpha$-matrix solute concentration that arose from a $2^{\circ} \mathrm{C}$ difference in final soak temperature. These "slow-cool and hold" experiments defined a critical $\alpha$-phase solute concentration, $\mathrm{C}_{\mathrm{c}}$, as the concentration in equilibrium with saturated $\beta$ phase in the $(\alpha+\beta+\chi)$ phase field at about $840^{\circ} \mathrm{C}$. This is $T_{c}$, the corresponding critical temperature. It should be a unique characteristic of the system, a function only of composition and test conditions.

Critical Temperature and $(\alpha+\beta+\chi) /(\alpha+\chi)$ Transus - Figure 6 is a graphical description of the visual matrix in Figure 4. The simplest function that matches the asymptotic 
characteristics of these data is of the form $\left(1-e^{-x}\right)$. The initial cooling rate was constant; the independent variable was hold time, the dependent variable, transition temperature. Analytical representation required three fitting parameters: $T_{0}$, the intercept at zero hold time $(t=0) ; T_{L}$, the limiting value for long hold times; and $\gamma$, an arbitrary coefficient of the hold time. The resulting empirical equation

$$
T=T_{L}-\left(T_{L}-T_{0}\right) \exp (-\gamma t)
$$

required at least three points to determine those parameters, one set for each mechanism. Taking $812^{\circ} \mathrm{C}, 825^{\circ} \mathrm{C}$, and $826^{\circ} \mathrm{C}(\mathrm{t}=0 \mathrm{hr}, 2 \mathrm{hr}$, and $5 \mathrm{hr})$ as the transition temperatures for sensitization with phase transformation yielded a $T_{L}$ value of $826^{\circ} \mathrm{C}$. This was $T_{\alpha}$, a "virtual" limit by this technique, inaccessible experimentally since the mechanism changed to simple sensitization by solute diffusion somewhere in the interval [ $5 \mathrm{hr}<\mathrm{t}<18 \mathrm{hr}$ ], but the rapid roll-over left little uncertainty about its value. The limiting value for the data with $t=$ $18 \mathrm{hr}$ and $48 \mathrm{hr}$ was $\mathrm{T}_{\mathrm{c}}$, experimentally approachable with very long hold times, but also easy to calculate with some certainty. It was necessary to supply a third point. The curves had to intersect beyond $\mathrm{t}=5 \mathrm{hr}$ with $\mathrm{T}=826^{\circ} \mathrm{C}$, and for transition-temperature estimates of $833^{\circ} \mathrm{C}$ and $837^{\circ} \mathrm{C}(\mathrm{t}=18 \mathrm{hr}, 48 \mathrm{hr}), \mathrm{T}_{\mathrm{L}}\left(\mathrm{T}_{\mathrm{c}}\right.$ in this case) was $837^{\circ} \mathrm{C}-838^{\circ} \mathrm{C}$ for any choice of $\mathrm{t}$ between $5 \mathrm{hr}$ and $18 \mathrm{hr}$.

\section{Isothermal Sensitization of Immune Zircaloy}

Zircaloy Close to Susceptibility - Figure 4 illustrates how several "slow-cool and hold" thermal treatments brought W2 Zircaloy-2 cladding material to the brink of sensitization. Figure 7 shows the temperature dependence of continuing that sensitizing process for two sets of $2 \mathrm{hr}$-hold specimens with different margins of immunity. Annealing for an additional, arbitrary, period of $18 \mathrm{hr}$; i.e., $\mathrm{BS}-826(2) \mathrm{F}+\mathrm{T}(18) \mathrm{F}$ and $\mathrm{BS}-829(2) \mathrm{F}+\mathrm{T}(18) \mathrm{F}$ showed that fan-cooling from $829^{\circ} \mathrm{C}$ left the second set of specimens slightly further from susceptibility to nodular corrosion in steam. After fan-cooling from $826^{\circ} \mathrm{C}$, the specimens in the first set showed more of a tendency toward sensitization by Ostwald ripening in the $(\alpha+\chi)$ phase field, but in both cases, susceptibility peaked at about $832^{\circ} \mathrm{C}$.

Highly-Resistant Zircaloy - Figure 8 makes isothermal annealing time a variable and shows that even $200 \mathrm{hr}$ of Ostwald ripening at temperatures just below the $(\alpha+\chi) /(\alpha+\beta+\chi)$ transus produced no visible signs of nodular corrosion in subsequent steam tests of $E \alpha$ cladding. Above the transus, mimicking the "barely immune" behavior in Figure 7, E $\alpha$ susceptibility became apparent from about $833^{\circ} \mathrm{C}$ to $835^{\circ} \mathrm{C}$ for a $25 \mathrm{hr}$ exposure. The temperature range of maximum susceptibility rose and broadened with annealing time, while at any given temperature, the severity of susceptibility increased with annealing time. In the limit of very long times, for annealing temperatures just below and just above $T_{c}$, solute-dependent sensitization must give rise to an abrupt transition from total susceptibility to complete immunity. The upward shift and sharpening of the susceptibilityreversal temperature with annealing time was consistent with these expectations, and 
placed $\mathrm{T}_{\mathrm{c}}$ at just above $841^{\circ} \mathrm{C}$ for this material, in close agreement with the slow cooling results.

Other Materials - Arbitrarily selecting $835^{\circ} \mathrm{C}$ as the best compromise for optimum sensitization yielded the test matrix in Figure 9. This photograph shows that the W2 cladding (far left) became susceptible faster than any of the four other commercial heats, and faster than the four custom heats containing deliberate nitrogen additions. It is interesting that the ZNR-based materials showed increasing resistance to sensitization with increasing homogeneous nitrogen content. After identical processing that simulated commercial tubing fabrication, these plate specimens contradicted earlier observations of increasing susceptibility with higher levels of nitrogen diffusion into the surface of production cladding [33]. The TWC plate specimen (eighth from left) showed an immunity in its rolling plane, an orientational dependence that originated with cold work. Wang et al. ascribed such effects to an increase in yield strength [34], but an increase in precipitate solubility with the storage of mechanical energy [35] would be more consistent with the solute model [2]. Quantitatively comparing the microstructures of all these specimens having various processing histories and different formats is beyond the scope of this paper. The results do suggest that determining a sensitization time with this simple procedure of steam testing after isothermal annealing at about $835^{\circ} \mathrm{C}$ in the $(\alpha+\beta+\chi)$ "sensitizing window" between $\mathrm{T}_{\alpha}$ and $\mathrm{T}_{c}$ would be one measure of immunity for any microstructure.

\section{Healing of Susceptible Zircaloy}

High $(\alpha+\beta)$ Heat Treatments - Taking highly susceptible Zircaloy-2 up to temperatures above both $T_{c}$ and the $(\alpha+\beta+\chi) /(\alpha+\beta)$ transus, then fan-cooling, restored complete immunity to nodular corrosion in steam. The heat-treatment sequences $\beta S F$ and $950(2) S F$ produced candidate specimens that would have developed heavy sheet oxide in a steam test. Additional heating to $950^{\circ} \mathrm{C}$, and immediate cooling to room temperature; i.e., + 950F, removed all susceptibility. Exposure to steam left only shiny black oxide on the nonbarrier surfaces. The investigation of microstructural memory includes the effect of that 950F healing-anneal on the respective microstructures.

Transient Partial Healing below $T_{c}$ - Isothermal exposure below $T_{c}$ eventually must decrease the matrix solute concentration to less than $C_{c}$ and cause the formation of sheet oxide in a subsequent steam test. Annealing at temperatures lower than $T_{c}$ cannot heal susceptible Zircaloy completely. Figure 10 shows, however, that a partial, temporary improvement is possible in this temperature range. Each specimen in the matrix received an initial $\beta S F$ sensitizing heat treatment prior to its pre-steam-test anneal at temperature $T$ for time $t$; i.e., $\beta S F T(t) F$. A value of $t=0$ signifies immediate cooling after reaching $T$.

There are gaps in the matrix, but the trends and limits are clear. Only at $844^{\circ} \mathrm{C}$ and above was the $t=0$ peaking profile sufficient to start healing the severe $\beta S F$ sensitization. 
For all except the two lowest temperatures below $839^{\circ} \mathrm{C}$, there was a progression with time from total susceptibility through partial healing to full resensitization that was complete after $100 \mathrm{hr}$. The pattern of this competition between healing and sensitization suggests that below $824^{\circ} \mathrm{C}$, healing was faster, but sensitization accelerated more with temperature and became dominant at about $824^{\circ} \mathrm{C}$. There was a striking, apparently discontinuous reversal just above this temperature, with healing evident even at $100 \mathrm{hr}$. A similar overtaking of healing by sensitization with increasing temperature peaked at about $832^{\circ} \mathrm{C}$, where the approach to $T_{c}$ and permanent healing finally became the major influence on nodular-corrosion susceptibility in steam within the time-frame of this experiment.

\section{Protection against Slow-Cooling Sensitization}

Protection of $\beta F$ against 950SF, and the $(\alpha+\beta+\chi) /(\alpha+\beta)$ Transus - The time and sequence scoping experiments implied that heating into the $(\alpha+\beta)$ phase field re-activated the $\beta F$ Widmanstatten structure and made $\beta F 950$ SF equivalent to $\beta S F$ in its ability to sensitize E $\alpha$ Zircaloy by slow cooling. Ostberg's suggestion that recrystallization could destroy the precipitate sheets and stringers characteristic of the $\beta F$ structure [25] prompted an investigation of pre-950SF annealing. Figure 11 , a photographic record of steam-test results, confirms that the precipitate distribution was instrumental in controlling the response of $\beta F$ Zircaloy to the $950 S F$ thermal profile.

Two hours at $750^{\circ} \mathrm{C}$ was ineffective, but a more aggressive recrystallization anneal for three hours at $790^{\circ} \mathrm{C}$ completely prevented $950 \mathrm{SF}$ sensitization. The $750(2)$ high$(\alpha+\chi)$ anneal had no readily discernible effect. The $\beta F 750(2) 950 S F$ microstructure was similar to the BSF (or BF950SF) microstructure of Figure 2. A longer exposure to a higher temperature seemed to preserve the Widmanstatten structure, but in Figure 12, 950SF after $\beta F 790(3)$ appears to have deposited coarser precipitates in the centers of the platelets, rather than along the platelet boundaries. Further experimentation with the $\beta F$ microstructure confirmed that this apparent redistribution occurred within a $\beta$-containing phase field. A $\beta F 805(15) F$ thermal profile coarsened the interlamellar precipitates considerably, but left them in grain boundaries. In all cases, $(\alpha+\chi)$ annealing of the $\beta F$ structure caused only minimal changes in the size and shape of the Widmanstatten $\alpha$ platelets.

Increasing the post- $\beta F$ annealing temperature extended confirmation of precipitate involvement into the $(\alpha+\beta+\chi)$ phase field. Values of $T$ in the $\beta F T(t) 950 S F$ thermal profile increased from $790^{\circ} \mathrm{C}$ to $820^{\circ} \mathrm{C}$ in steps of $10^{\circ} \mathrm{C}$ with t at $3 \mathrm{hr}$, then from $830^{\circ} \mathrm{C}$ to $850^{\circ} \mathrm{C}$ in steps of $5^{\circ} \mathrm{C}$ with $\mathrm{t}$ at $2 \mathrm{hr}$. According to Figure 11 , the pictorial summary of these $\beta \mathrm{F}$ protection experiments, the change from immunity to formation of abundant nodules on the external radial surface of the $\mathrm{W} 2$ cladding occurred at about $850^{\circ} \mathrm{C}$, close to Ostberg's estimate [25] of $T_{\chi}$, the temperature of the $(\alpha+\beta+\chi) /(\alpha+\beta)$ transus. A re-appearance of 
larger, intergranular precipitates in the final microstructures marked this transition, but there was no direct evidence that the $\chi$ phase had dissolved completely prior to heating into the high $(\alpha+\beta)$ phase field.

Protection against 950(2)SF - Preceding the 950(2)SF thermal profile with a 12-hour high- $(\alpha+\chi)$ recrystallization anneal at $820^{\circ} \mathrm{C}$ developed $\alpha$ grains in the E $\alpha$ cladding whose dimensions approached, or even exceeded, the tubing wall thickness, and completely nullified the sensitizing effect of slow-cooling. Twelve hours at $820^{\circ} \mathrm{C}$ could not protect $\beta F$ and $950(2) F$ specimens completely against very aggressive $950(2) \mathrm{SF}$ sensitization. Since Widmanstatten microstructures resist grain growth in the $(\alpha+\chi)$ phase field, and the $820(12)$ precipitate ripening exposure was the same for $E \alpha$ as for $\beta F$, this result implies that grain size can also make an important contribution to the protection mechanism.

Protection against $\beta S F$ - Three hours at $800^{\circ} \mathrm{C}$ had immunized $\beta \mathrm{F}$ against $950 \mathrm{SF}$ sensitization by ripening the intergranular precipitates. There was no reason to anticipate a similar benefit from preceding a $\beta$ heat treatment with a high- $(\alpha+\chi)$ anneal, but the protection of $E \alpha$ cladding against $\beta S F$ sensitization was equally effective. Figure 12 quite accurately represents the final 800 (3)BSF microstructure in bright field at low magnification, but Figure 13 reveals that slow cooling actually left small equiaxed grains with large intragranular precipitates in patterns that outlined the shapes of prior Widmanstatten platelets. Previous precipitate ripening and $\alpha$-grain growth had influenced the microstructural trajectory of the 800 (3) $\beta S F$ specimen during and after its exposure in the $\beta$ phase field.

\section{Microstructural Memory}

High $(\alpha+\beta)$ Heat Treatments - The scoping experiments showed no detectable difference, either in microstructure or sensitization behavior, between $\beta S F$ and $B F 950 S F$ slow-cooling heat treatments. The interlamellar precipitates occupied prior- $\beta$ regions in the $\beta F$ structure (Figure 1), and their dissolution with the reappearance of $\beta$ phase provided a "memory" of previous conditions at $950^{\circ} \mathrm{C}$.

The investigation of healing led to the discovery of a far more subtle form of microstructural memory. The $\beta S F$ and $950(2) S F$ thermal profiles produced candidate specimens that would have developed heavy sheet oxide in the steam test, and it was no surprise that heating above both $\mathrm{T}_{\mathrm{c}}$ and the $(\alpha+\beta+\chi) /(\alpha+\beta)$ transus to $950^{\circ} \mathrm{C}$, then fancooling, restored complete immunity. The effect of that $950 \mathrm{~F}$ healing-anneal on the respective microstructures (cf. Figure 2(b)) was truly remarkable.

Figures 14 and 15, micrographs after $\beta S F 950 \mathrm{~F}$ and $950(2)$ SF950F heat treatments, document restorations of the original, pre-slow-cool microstructures! The lamellae in Figure 14 have widths similar to those in Figure 1, and their boundaries show the 
segregation of Figure 5 at a much earlier stage. Figure 15 is indistinguishable from images of the $950(2) \mathrm{F}$ microstructure. Thus, although the healing was complete, it re-created microstructures susceptible to slow-cooling sensitization. Taking the sequence to its logical conclusion confirmed the efficacy of this memory effect with an obvious result: specimens receiving either BSF950SF or 950(2)SF950SF heat treatments developed heavy sheet oxide in steam.

Solution Heat Treatment in the $\beta$ Phase Field - The initial investigation of slow-cooling sensitization supported an implicit assumption that heating to a peak temperature of $1010^{\circ} \mathrm{C}$ had established a reproducible, generic microstructure. The $\beta S F$ thermal profile became the standard for generating highly susceptible W2 Zircaloy-2, but high- $(\alpha+\chi)$ protection against $\beta S F$ sensitization of E $\alpha$ cladding required that a "memory" of that $(\alpha+\chi)$ anneal persist through the brief $\beta$ heat treatment. This conclusion, and the T22 ingot's much greater resistance to isothermal sensitization at $835^{\circ} \mathrm{C}$ in the $(\alpha+\beta+\chi)$ sensitizing window (Figure 9), prompted slow-cooling experiments with other sources of Zircaloy -2 and their re-melt derivatives. The representative specimens in the $t=0$ (second) row of Figure 16 demonstrate that the BSF heat treatment generated responses from specimens with similar geometries, and similar or identical chemical compositions, that ranged from immunity to heavy sensitization. Clearly, there were different starting points for the "SF" part of the profile.

Figure 16 presents a pictorial matrix of steam-test results after $\beta(t) S F$ heat treatments. This specimen photo shows that when sensitization occurred, it peaked, then disappeared with increasing time at $1010^{\circ} \mathrm{C}$. Given sufficient time in the $\beta$ phase field, Zircaloy-2 from all sources lost enough "memory" of prior processing to attain a starting point that was immune to SF sensitization. This "equalization" was specific to that particular SF thermal profile, and did not signify a common microstructure.

Cladding materials $\mathrm{T} 1$ and $\mathrm{T} 2$ had similar processing histories and essentially identical chemistries. With fine-grained $\mathrm{E} \alpha$ microstructures optically indistinguishable from W2 tubing, they offered an opportunity for comparing their contrasting behaviors directly with earlier results. T1 sensitized much as W2, but T2 remained immune to nodular corrosion. Close examination of the $\beta S F$ microstructures revealed a key difference. Tl acquired the "normal" agglomerates at triple points and retained primarily intergranular precipitates at the boundaries of Widmanstatten platelets. Earlier-vintage T2 cladding developed equiaxed grains with distinct patterns of large intragranular precipitates that outlined the shapes of prior Widmanstatten platelets, just as in Figure 13. This behavior suggested a difference in annealing history, and was consistent with a conscious effort in that time frame to reduce exposure in the high $(\alpha+\chi)$ phase field during commercial tubing fabrication.

Triple arc re-melting commercial non-barrier tubeshell left ZNR with a very fine acicular Widmanstatten microstructure. The third column from the left in Figure 16 shows the slower cyclic response of specimens from this small experimental ingot to the $\beta(t) S F$ 
profile. Once again, the appearance of large agglomerates at low magnification accompanied the onset of susceptibility, this time for $\beta(0.25) S F$ and $\beta(1) S F$. Longer exposure at $1010^{\circ} \mathrm{C}$ restored immunity to SF sensitization and left regions of non-acicular substructure with small equiaxed grains and fewer large precipitates. After processing to simulate commercial tubing fabrication, ZNR-based plate responded in a similar fashion (Figure 16, fourth column from left). As for isothermal sensitization (Figure 9), the homogeneous addition of nitrogen improved the ZNR plate's resistance to slow-cooling sensitization (Figure 16, fifth column).

The platelets and platelet patterns in all materials generally coarsened with annealing time at $1010^{\circ} \mathrm{C}$. This dependence of lamellar width on factors other than temperature and cooling rate implied a contribution from the spatial distribution of alloying elements [30].

\section{Precipitate Coarsening}

For Zircaloy-2, the combination of coarse precipitates and sufficient solute for immunity to nodular corrosion in steam is attainable by isothermal annealing. The final coarsening anneal must be at a temperature higher than $T_{c}$ to produce a totally immune matrix, but cannot exceed the temperature of the $(\alpha+\beta+\chi) /(\alpha+\beta)$ transus for too long, or an entirely different precipitate distribution will form on cooling. The available "window" is very narrow, approximately $\left[840^{\circ} \mathrm{C}<\mathrm{T}<850^{\circ} \mathrm{C}\right]$, and lies entirely within the $(\alpha+\beta+\chi)$ phase field.

Annealing W2 cladding for three hours in the $(\alpha+\chi)$ phase field at $800^{\circ} \mathrm{C}$ grew many large grains, but Figure 17(a) shows several regions with tiny equiaxed grains very similar in size to the originals. Subsequent protective coarsening for 1.5 hours at $840^{\circ} \mathrm{C}$ evoked two distinctly different precipitate responses as it immunized the matrix against nodular corrosion in steam. Figure 17(b) shows that most intragranular precipitates within the new large grains remained discrete as they continued to ripen, whereas many precipitates in the small grains migrated to intergranular $\beta$ phase and formed large, triplepoint agglomerates in the final $(\alpha+\chi)$-phase microstructure. Six hours at $800^{\circ} \mathrm{C}$ was sufficient to recrystallize all grains, and the same protective coarsening anneal left a uniform distribution of large intragranular precipitates with only traces of triple-point segregation.

The thin, elongated $\alpha$ platelets of the $\beta F$ Widmanstatten structure provided an example of how grain shape can influence the microstructural trajectory in the presence of $\beta$ phase. The small E $\alpha$ grains in Figure 17(a) were already spherical and segregated $\chi$ phase to triple points. In the same length of time at $840^{\circ} \mathrm{C}$, the platelets in the $\beta F$ structure (cf. Figure 1) started to broaden and subdivide. This dynamic restructuring left no stable locations for aggregation and the precipitates remained discrete, ripening uniformly in their original locations. 


\section{DISCUSSION}

Slow-Cooling Sensitization - Slow-cooling Zircaloy after a $\beta$ heat treatment provided the first, and most important, evidence of the sensitization mechanism. When fan-cooling occurred at a temperature higher than that of the $(\alpha+\beta+\chi) /(\alpha+\chi)$ phase transformation for a given cooling rate and hold time, the micrographs showed that most of the visible $\chi$ phase remained at the Widmanstatten platelet boundaries as in Figure 5. These intergranular regions had comprised a penetrating network of contiguous $(\beta+\chi)$ phase, a shell structure surrounding the $\alpha$ platelets, and there was insufficient opportunity for redistribution of $\chi$ phase into the adjacent $\alpha$-phase regions after the final conversion of $\beta$ to $\alpha$ at lower temperatures. As the system cooled in the $(\alpha+\beta)$ phase field and passed through the $(\alpha+\beta) /(\alpha+\beta+\chi)$ phase transformation, the concentrations of the $\beta$-stabilizing elements $(\mathrm{Fe}, \mathrm{Cr}, \mathrm{Ni})$ reached saturation, their activities reached unity, and precipitation of $\chi$ phase initiated in the $\beta$ phase. The absence of significant $\chi$ in the $\alpha$ phase that was present prior to fan-cooling also means that segregation to the $\beta$ phase continued as all the solubilities decreased with temperature in the $(\alpha+\beta+\chi)$ phase field. Maintaining this $\alpha$-to- $\beta$ activity gradient in the presence of an opposing concentration gradient required a large imbalance in activity coefficients. Finite cooling rates through the $(\alpha+\beta+\chi) /(\alpha+\chi)$ phase transformation permitted additional solute reduction in the prior- $\alpha$ matrix by homogeneous nucleation of small intragranular precipitates.

For final hold-times of more than 5 hours, the specimens sensitized in the $(\alpha+\beta+\chi)$ phase field with no observable transformation as the matrix solute concentration dropped below $\mathrm{C}_{\mathrm{c}}$. For final hold times of 5 hours or less, the onset of susceptibility appeared to coincide with the disappearance of $\beta$ phase. Initially confusing, this combination probably occurred sequentially when diffusion kinetics kept the $\alpha$-matrix solute concentration just above $C_{c}$ as the system cooled to temperatures below the $(\alpha+\beta+\chi) /(\alpha+\chi)$ phase transformation. The cooling rates were sufficiently slow for an approach to steady state after homogeneous $\chi$ nucleation in the previously precipitate-free $\alpha$ matrix. At temperatures well below $T_{c}$, this precipitation and the early stages of Ostwald ripening decreased the solute concentration to less than $\mathrm{C}_{\mathrm{c}}$ and sensitized the matrix to nodular corrosion in steam. For some critical cooling rate faster than $0.005^{\circ} \mathrm{C} / \mathrm{s}$, residual posttransformation solute concentration would exceed $\mathrm{C}_{c}$, and sensitization would not occur.

Widmanstatten Precipitate Memory - Microstructural examination could not differentiate between the thermal-sensitization sequences $\beta S F$ and $\beta F 950 S F$ (cf. Figure 2). Reheating the $\beta F$ structure high into the $(\alpha+\beta)$ phase field re-created the Widmanstatten $\alpha$-platelet configuration with surrounding, contiguous $\beta$ phase that existed at that temperature during initial cooling. It was clear from the slow-cooling experiments that when the respective phases co-existed, this system minimized its free energy by bounding $\alpha$ grains with a coherent shell of epitaxial, allotropic $\beta$ phase, and by partitioning all $\chi$ to the $\beta$ phase. Thus, upon reheating, $\beta$ formed first at $\alpha / \chi$ interfaces and in $\alpha / \alpha$ grain boundaries. Since 
most precipitates already occupied interlamellar regions, dissolution of $\chi$-phase, and reformation of a microstructure very close to the original, required only a brief return to $950^{\circ} \mathrm{C}$.

Susceptible Microstructures - The short paths from the interiors of thin $\alpha$ platelets to the surrounding invasive, contiguous network of $(\beta+\chi)$ promoted efficient diffusional solute segregation from $\alpha$ to $\beta$ in the $(\alpha+\beta+\chi)$ phase field during the $\beta S F$ heat treatment. Although it had appeared so initially, the Widmanstatten microstructure was not unique in its susceptibility to sensitization by slow cooling. While the $950 \mathrm{SF}$ sequence left the $\mathrm{E} \alpha$ material immune to nodular corrosion in steam, $\beta S F$ and 950 (2)SF were equally effective sensitizing heat treatments. Figure 15 accurately represents $950(2) \mathrm{F}$, the pre-SF counterpart of $\beta F$ in Figure 1; i.e., the residual microstructure after cooling quickly from a state susceptible to slow-cooling sensitization. As for the $\beta F$ structure, all the visible precipitates decorated grain boundaries in continuous strings, but the grains in Figure 15 are equiaxed, not elongated. Developing a geometry analogous to the Widmanstatten structures from the E $\alpha$ microstructure (cf. small grains in Figure 17(a)) simply required more time with $\beta$ phase present than 950SF had allowed.

The brief $(\alpha+\beta)$ plus slow-cooling 950SF heat treatment developed uniform, coarse precipitates from the original $E \alpha$ starting material's random distribution of fine precipitates, while retaining general immunity to nodular corrosion in steam. Upon heating the production cladding into the $(\alpha+\beta)$ phase field, $\beta$ phase would have replaced the $\alpha / \alpha$ grain boundaries, surrounded the primarily intragranular precipitates, and formed " $\beta$ islands" at these sites as the $\chi$ phase dissolved. Driven by radii-dependent surface energies in a process analogous to the Ostwald ripening of precipitates in the $(\alpha+\chi)$ phase field, solute diffusion coarsened the island distribution. While slow cooling back through the $(\alpha+\beta+\chi)$ phase field at the SF rate, the mean $\alpha$-source to $(\beta+\chi)$-sink distance was sufficiently large to prevent the reduction of solute to concentrations below $C_{c}$.

Subsequent passage through the $(\alpha+\beta+\chi) /(\alpha+\chi)$ transformation left large, discrete precipitates in the $\alpha$ matrix, again with a random spatial distribution.

With a two-hour exposure at $950^{\circ} \mathrm{C}$, there was sufficient time for the free-energyreducing ripening process to transfer most $\beta$ islands to the $\alpha$ - $\alpha$ interphase $\beta$-shell network with its concave surfaces. The distances from the interiors of the $\alpha$ grains to the surrounding, contiguous, $\beta$ shell were similar to those in the equivalent Widmanstatten structures. The strings of intergranular precipitates in Figures 14 and 15 constitute a residual image of their $\alpha$-grain / $\beta$-shell precursors. Cooling either precursor structure from $830^{\circ} \mathrm{C}$ to $800^{\circ} \mathrm{C}$ at a rate of $0.005^{\circ} \mathrm{C} / \mathrm{s}$ provided sufficient time for diffusion to both reduce the solute concentration in the $\alpha$ grains to less than $\mathrm{C}_{\mathrm{c}}$ and develop large $\chi$ agglomerates like those in Figure 2. 
Ostwald Ripening and Susceptibility - For spherical precipitates in the $(\alpha+\chi)$ phase field, the Gibbs-Thompson equation

$$
\mathrm{C}=\mathrm{C}^{\circ}(\mathrm{T}) \exp (\mathrm{A} / \mathrm{rT})
$$

defines their solubility; i.e., the solute concentration at the $\alpha$ matrix $/ \chi$ interface, as a function of temperature and radius. Those precipitates with solubilities higher than the solute concentration in the adjacent matrix dissolve and shrink, while those with lower solubilities grow.

Simple models use the mean solute concentration (total additive minus precipitates) to calculate the concentration gradient for a rate equation. Solubility equal to the mean defines a metastable, characteristic radius for the precipitate size distribution. Both quantities are functions of time. The solute concentration decreases, and the characteristic size increases, as the precipitate distribution coarsens. The population of small precipitates also decreases, but shrinkage and disappearance is a continuing process that cannot terminate in finite times.

Figure 18 summarizes the predicted relationship between Ostwald ripening, and susceptibility to nodular corrosion in steam. Since $T_{c}$ is above the $(\alpha+\chi) /(\alpha+\beta+\chi)$ transus, the limiting solubility $C^{\circ}(T)$ (equilibrium with a planar $\chi$ surface) at any temperature $T$ in the $(\alpha+\chi)$ phase field lies below the critical concentration, $C_{c}$, and $\alpha$-Zircaloy eventually will sensitize. Residual $C>C_{c}$ after fast cooling from above $T_{c}$ temporarily immunizes $\alpha$ Zircaloy against nodular corrosion. If, at the new temperature in the $(\alpha+\chi)$ phase field, most precipitates are small enough to have solubilities greater than $C_{c}$ (upper-left corner of Figure 18); e.g., after a very fast $\beta$ quench, sensitization will be very slow. If, on the other hand, most precipitates are large enough to have solubilities less than $C_{c}$ after slower cooling from just above $T_{c}$, the matrix solute concentration will drop below $C_{c}$ more quickly, and sensitization will be faster. The graphical example illustrates final-phase steady-state susceptibility.

In general, the degree of nodular coverage after exposure to steam should reflect the precipitate-distribution functions, both spatial and size. Nodules will nucleate at matrix sites with local solute concentrations less than $C_{c}$. In the early stages of sensitization, these will be adjacent to the largest precipitates. Once the mean solute concentration is less than $\mathrm{C}_{c}$, there should be nodule coalescence and sheet oxide with black, protective oxide adjacent only to precipitates small enough to have solubilities greater than $C_{c}$.

Isothermal Sensitization and Healing - Annealing time and temperature in the threephase $(\alpha+\beta+\chi)$ region are critical pre-cool variables. A brief exposure just above $T_{c}$ immunizes the matrix and causes little change in a high-density precipitate distribution, but leaves the structure susceptible to rapid thermal sensitization by Ostwald ripening. A longer exposure above $T_{c}$ allows $\beta$-island growth, and leaves wide gaps between large precipitates, an immune structure that will resist sensitization in the $(\alpha+\chi)$ phase field for a 
longer time. At temperatures below $T_{c}$, rapid equilibration of the matrix solute with $\beta$ island sinks sensitizes the matrix. The rate of sensitization increases with temperature as the diffusion rates increase, but the process must slow, and its rate approach zero, as the isothermal annealing temperature increases and approaches $T_{c}$. The model predicts that the peak rate of isothermal sensitization to nodular corrosion in steam must occur between $T_{a}$ and $T_{c}$.

Transient Healing below $T_{c}$ - At temperatures less than $T_{c}$, healing of a susceptible matrix can occur only adjacent to dissolving precipitates. The BSF $\alpha$ grains were devoid of precipitates until homogeneous nucleation became energetically favorable. If not before, this occurred after completion of the $(\alpha+\beta+\chi) /(\alpha+\chi)$ phase transformation. These intragranular precipitates were all small, having nucleated rapidly at low temperatures. Upon reheating to just below $T_{\alpha}$ their solubilities were high, many greater than $C_{c}$. Establishing a trajectory toward $(\alpha+\beta+\chi)$ equilibrium above $T_{\alpha}$ required their assimilation by a reforming $(\beta+\chi)$ shell network. Whether they dissolved directly by Ostwald ripening in the $(\alpha+\chi)$ phase field, or first became $\beta$ islands and dissolved by the surface-energy driven $\beta$-ripening mechanism in the $(\alpha+\beta+\chi)$ phase field, these transient sources of solute temporarily healed their prior locations in the matrix.

Competing Processes - Both transient healing from solute injection and resensitization by the consumption of protective solute accelerated with temperature, but the latter increased faster in both the $(\alpha+\chi)$ and $(\alpha+\beta+\chi)$ phase fields. The discontinuity in Figure 10 at about $825^{\circ} \mathrm{C}$ coincided with the $(\alpha+\chi) /(\alpha+\beta+\chi)$ transus-temperature estimate from slow-cooling sensitization. With the change from Ostwald to $\beta$ ripening, solute injection dominated once again, and healing persisted beyond $100 \mathrm{hr}$.

Figures 7,8 and 10 reflect the rapid increase in sensitization rate with temperature just above the transus. The peaking and reversal that became evident for an $18 \mathrm{hr}$ anneal at about $833^{\circ} \mathrm{C}$ (Figure 7) occurred over a wider range at higher temperatures for longer exposure times (Figures 8 and 10). Approaching $T_{c}$ intensified the healing effect as the $\alpha \rightarrow \beta$ activity gradient for $\alpha$-matrix solute at concentrations below $C_{c}$ became small enough to slow, then stop measurable sensitization. Figure 10 documents a remarkable healing/resensitization transient at $836^{\circ} \mathrm{C}$ where proximity to $T_{c}$ was allowing solute injection from tiny precipitates to dominate the kinetics completely at $3 \mathrm{hr}$.

Accelerated Test for Corrosion Margin - The steam test is an ultra-sensitive indicator of susceptibility to nodular corrosion, but on its own, cannot differentiate between materials that are safely immune and those that are on the verge of total susceptibility. The sensitizing "window" $\left[T_{c}>T>T_{\alpha}\right]$ offers a simple approach to quantitative evaluation. For a given temperature in this range, the degree of susceptibility as a function of pre-test annealing time rapidly reflects both the initial concentration of solute in the matrix and the propensity of the precipitate distribution to absorb solute in the $(\alpha+\beta+\chi)$ phase field. 
In-reactor there is no $\beta$ phase, and at $288^{\circ} \mathrm{C}$, neutron bombardment must control precipitate dissolution and ripening. These experiments showed that thermal sensitization by Ostwald ripening in the $(\alpha+\chi)$ phase field more accurately reflected different margins of immunity in specimens with very different microstructures, but high- $(\alpha+\chi)$ annealing for hundreds or thousands of hours is not a realistic option for comparative screening. The intuitively correct trends over relatively short times in Figures 7 and 9 provide justification for further investigation. Following successful initial calibration at $835^{\circ} \mathrm{C}$ with archive materials for which in-pile corrosion data are available, three or four time intervals; e.g., $15,30,60,(90) \mathrm{hr}$, probably would suffice for routine quantitative evaluation.

Precipitate Coarsening - Restricting temperatures to the $\chi$-containing phase fields separated the coarsening experiments from the investigations of protection and memory by retaining precipitates through all transformations. Their presence in intergranular regions dominated grain growth and shape change, and once in those locations, they tended to remain at grain interfaces.

Precipitate coarsening by Ostwald ripening is uniform in the $(\alpha+\chi)$ phase field, but only $\beta$-ripening between $T_{c}$ and the $(\alpha+\beta+\chi) /(\alpha+\beta)$ transus can coarsen a precipitate distribution while leaving sufficient matrix solute for immunity to nodular corrosion after rapid cooling. In the $(\alpha+\beta+\chi)$ phase field, small equiaxed grains promoted triple-point segregation and the formation of large precipitate structures with concave surfaces. Subsequent Ostwald ripening sensitized immune matrices with similar agglomerates much more quickly than the original $\mathrm{E} \alpha$ microstructure with its discrete spherical precipitates (Figures 7 and 8). Figure 10 provides evidence for rapid healing of sensitized Zircaloy above $T_{c}$, and suggests the possibility of avoiding undesirable microstructures by protective annealing after uniform precipitate growth by Ostwald ripening in the $(\alpha+\chi)$ phase field. The precipitate coarsening experiments demonstrated that appropriate annealing sequences can combine immunity to nodular corrosion in steam with almost any desirable precipitate distribution.

Protection of $\beta F$ from 950SF Sensitization - The recrystallizing anneals in the $\chi$ containing phase fields delayed attainment of a microstructure susceptible to slow-cooling sensitization by ripening the $\beta \mathrm{F}$ precipitates and preventing their rapid dissolution and assimilation into a uniform $\alpha$-platelet / $\beta$-shell configuration at higher temperatures. Figure 12 shows that $\beta F 790$ (3) platelet restructuring during a 950SF heat treatment left very large precipitates in their original Widmanstatten patterns, far from the new grain boundaries. Whether or not these thermodynamically unstable precipitates dissolved in surrounding $\beta$ phase during their short excursion into the $(\alpha+\beta)$ phase field, the corresponding $\beta$ islands remained stationary and discrete during cooling, and the precipitates reappeared at their original sites. Annealing for several hours in the $(\alpha+\beta)$ phase field prior to the final 950SF heat treatment cancelled the benefit of recrystallization by dissolving all $\beta F$ precipitates in the interlamellar $\beta$ phase and making the $\beta F T(2) 950 \mathrm{SF}$ profiles with $\mathrm{T}>\mathrm{T}_{x}$ equivalent to $\beta \mathrm{F} 950 \mathrm{SF}$. 
Protection of $E \alpha$ from 950(2)SF Sensitization - With a strong driving force to minimize interfacial energy in $\alpha$ grain boundaries by rapid grain growth, annealing the $E \alpha$ tubing for $12 \mathrm{hr}$ at $820^{\circ} \mathrm{C}$ high in the $(\alpha+\chi)$ phase field dramatically reduced the density of triple points, isolated ripening precipitates in the matrix, and assured the formation of an expansive $\beta$ shell containing minimal solute at $950^{\circ} \mathrm{C}$. The microstructural antithesis of susceptible Zircaloy with its small grains and intergranular precipitates, this material was completely immune to 950 (2)SF sensitization after "high- $\alpha$ protection" developed a random distribution of coarse, intragranular precipitates within very large grains.

$\beta$ Heat Treatments and Dynamic Solute Clusters - The high $\beta$-solubility of alloying elements and discrete $\beta$ islands created a memory of precipitate locations during brief excursions into the $(\alpha+\beta)$ phase field. Only similar prior-precipitate sites, local matrix volume elements with very high solute concentrations or "solute clusters [21]," could account for the retention of microstructural memory during a solution heat treatment in the $\beta$ phase field. Figure 16 confirms that such reflections of processing history did occur, and that these "fingerprints" persisted for remarkably long times. Even two hours at $1010^{\circ} \mathrm{C}$ failed to bring any of these specimens to a common starting point, and hence, the same final microstructure. It is clear, though, that diffusion eventually must homogenize the matrix in a single-phase region, and with the possible exception of $\beta$ grain size, all Zircaloy with the same chemical composition will become equivalent for subsequent thermal processing. Two hours at $1010^{\circ} \mathrm{C}$ was sufficient only for equalization by the arbitrary $\beta S F$ criterion.

The lamellae-mimicking precipitate patterns in Figure 13, the immune microstructure of W2 cladding after 800(3)BSF thermal treatment, offer indirect evidence that precipitates dissolved to form submicroscopic clusters of solute atoms (GuinierPreston zones) in the $\beta$ phase field. The 3-hour anneal at $800^{\circ} \mathrm{C}$ had ripened the $\mathrm{E} \alpha$ precipitate distribution significantly; so much so, that the $\beta S F$ thermal treatment apparently deposited large, stable islands within the $\beta$ continuum between platelets in the initial Widmanstatten structure. Boundary motion in the $(\alpha+\beta)$ phase field isolated these static islands, and further cooling created an image of the first platelets as the new intragranular precipitates appeared. The immune T2 BSF microstructure appeared to have this same characteristic intragranular precipitate image of prior platelets, but its history of longer anneals at higher temperatures did not produce an initial $\mathrm{E} \alpha$ precipitate distribution that was visibly coarser than the more recent, and more susceptible, $\mathrm{Tl}$ cladding.

Hidden Memory and Metastable Solute Clusters - Dissolution of $\chi$ phase in the $(\alpha+\beta)$ and $\beta$ phase fields promoted subsequent restructuring, and participated in both the formation and activation of memory. It is important to emphasize that responses to the very specific and arbitrary SF slow-cooling thermal profile conveniently provided most visual examples of memory effects in this investigation, but the principles should apply to all microstructural manipulation of Zircaloy. 
Re-creation of the very distinctive $\beta F$ and $950(2) \mathrm{F}$ microstructures from $\beta S F$ and 950 (2)SF starting points by a rapid 950F exposure high in the $(\alpha+\beta)$ phase field (Figures 14 and 15) was a surprise. Unlike the direct restoration of a $\beta F$ Widmanstatten structure from a clear pattern of interlamellar precipitates (e.g., BF950SF sensitization), these transformations occurred without the benefit of any recognizable characteristics in the respective SF micrographs. During careful TEM examinations of Zircaloy-2 tubing, Herb et al. [21] detected micro-zones of solute enrichment at concentrations above the solubility limits that Charquet $e t$ al. [5] had reported for $\alpha$ zirconium. Only such local regions of particularly high solute concentration could have acted as non-precipitate sites for $\beta$ nucleation upon reheating above $T_{\alpha}$. SF slow cooling must have retained $\alpha$-phase solute-cluster images of the prior microstructures. The activation of such phantom images in the $\beta$-containing phase fields may well have constituted a significant fraction of all lingering "fingerprint" memories, including those of the micrographically identical T1 and T2 cladding specimens.

\section{SUMMARY AND CONCLUSIONS}

Slow cooling Zircaloy- 2 sensitizes it to nodular corrosion in steam by allowing the concentration of $\beta$-stabilizing solute elements in the $\alpha$ matrix to fall below a critical value that is characteristic of the test conditions. This is the equilibrium value at the corresponding critical temperature $\mathrm{T}_{\mathrm{c}}$, typically about $840^{\circ} \mathrm{C}$ and some $15^{\circ} \mathrm{C}$ above the $(\alpha+$ precipitate) phase field. Immunity to nodular corrosion is a metastable condition requiring cooling from above the critical temperature that is sufficiently rapid to retain a protective level of solute. When present together, precipitates partition to the $\beta$ phase, and both preferentially occupy the regions between $\alpha$ grains. Structures like Widmanstatten "basket weave" or "parallel plate" formations that minimize the distance between grain interiors and ( $\beta+$ precipitate) sinks are particularly susceptible to slow-cooling sensitization.

Isothermal experiments confirmed a value of about $840^{\circ} \mathrm{C}$ for the critical temperature of typical Zircaloy-2. Annealing susceptible Zircaloy at a higher temperature eventually raises the matrix solute concentration of $\beta$-stabilizing alloying elements above the critical value for immunity to nodular corrosion in steam. Sufficiently rapid cooling then retains adequate solute for metastable protection. Annealing below $T_{c}$ inevitably sensitizes immune Zircaloy. Ostwald ripening slowly consumes excess solute in the $\left(\alpha+\right.$ precipitate) phase field. Above the transus temperature, $T_{a}, \beta$ phase surrounds the precipitates and the ( $\beta+$ precipitate) regions quickly absorb solute as they equilibrate with $\alpha$ phase and act as sinks for the excess. The maximum rate of sensitization occurs at about $835^{\circ} \mathrm{C}$ in the window between $\mathrm{T}_{a}$ and $\mathrm{T}_{c}$. Homogeneous nitrogen additions improve resistance to sensitization at $835^{\circ} \mathrm{C}$. 
Annealing Zircaloy-2 in the window between the critical temperature $T_{c}$ and the precipitate dissolution temperature $\mathrm{T}_{\chi}$, about $850^{\circ} \mathrm{C}$, rapidly coarsens the precipitate distribution while retaining sufficient solute in the matrix for post-cooling immunity to nodular corrosion in steam. Such "protective coarsening" tends to form precipitate agglomerates at triple points in equiaxed microstructures. Prior recrystallization below $\mathrm{T}_{u}$, about $825^{\circ} \mathrm{C}$, in the ( $\alpha+$ precipitate) phase field promotes uniform protective coarsening by increasing the distances to grain boundaries and reducing the number of triple points. Reversion of metastable Widmanstatten platelets to equiaxed grains during protective coarsening isolates interlamellar precipitates, prevents agglomeration, and obviates the need for prior recrystallization.

Dissolving precipitates create local regions of high solute concentration, solute clusters that form a metastable $\alpha$-phase memory. Activation by heating into a $\beta$-containing phase field can re-establish a former microstructure. Recrystallization in the $(\alpha+$ precipitate) phase field ripens precipitates, homogenizes the solute, destroys prior memory, and dramatically changes properties like susceptibility to slow-cooling sensitization. Transient clusters in the $\beta$ phase field, from either dissolving precipitates or prior $\alpha$ clusters, persist through short solution heat treatments and retard microstructural equalization. Zircaloy can carry a contribution to its cumulative memory from the initial melt, a "vendor fingerprint" that subtly influences all subsequent responses to thermal processing.

\section{ACKNOWLEDGEMENTS}

The author gratefully acknowledges both financial support for this work from GE Nuclear Energy, and many helpful discussions with R.B. Adamson, Vallecitos Nuclear Center, C.D. Williams, Wilmington NC, and their colleagues at GENE. The author also wishes to thank R. Kucharski of GENE and R.C. Schnoor of GE-CRD for the optical metallography that was critical to understanding Zircaloy's nodular corrosion behavior in steam.

\section{REFERENCES}

[1] B.-C. Cheng, R.M. Kruger and R.B. Adamson, in: Proc. 10th Int. Symp. on Zirconium in the Nuclear Industry, ASTM-STP 1245 (American Society for Testing and Materials, Philadelphia, 1994) p. 400.

[2] D.F. Taylor, J. Nucl. Mater. 184 (1991) 65.

[3] R.M. Kruger, R.B. Adamson and S.S. Brenner, J. Nucl. Mater. 189 (1992) 193.

[4] B. Wadman and H.-O. Andren, in: Proc. 9th Int. Symp. on Zirconium in the Nuclear Industry, ASTM-STP 1132 (American Society for Testing and Materials, Philadelphia, 1991) p. 461.

[5] D. Charquet, R. Hahn, E. Ortlieb, J.-P. Gros and J.-F. Wadier, in: Proc. 8th Int. 
Symp. on Zirconium in the Nuclear Industry, ASTM-STP 1023 (American Society for Testing and Materials, Philadelphia, 1988) p. 405.

[6] J.H. Harding, J. Nucl. Mater. 202 (1993) 216.

[7] R.A. Graham, J.P. Tosdale and P.T. Finden, in: Proc. 8th Int. Symp. on Zirconium in the Nuclear Industry, ASTM-STP 1023 (American Society for Testing and Materials, Philadelphia, 1989) p. 334.

[8] K. Ogata, in: Proc. 8th Int. Symp. on Zirconium in the Nuclear Industry, ASTMSTP 1023 (American Society for Testing and Materials, Philadelphia, 1989) p. 346.

[9] H.G. Weidinger, H. Ruhmann, G. Cheliotis, M. Maguire and T.-L. Yau, in: Proc. 9th Int. Symp. on Zirconium in the Nuclear Industry, ASTM-STP 1132 (American Society for Testing and Materials, Philadelphia, 1991) p. 499.

[10] T. Isobe, T. Murai and Y. Mae, in: Proc. 11th Int. Symp. on Zirconium in the Nuclear Industry, ASTM-STP 1295 (American Society for Testing and Materials, Philadelphia, 1996).p. 203.

[11] Y. Etoh, S. Shimada, T. Yasuda, T. Ikeda, R.B. Adamson, J.-S.F. Chen, Y. Ishii and K. Takei, in: Proc. 11 th Int. Symp. on Zirconium in the Nuclear Industry, ASTM-STP 1295 (American Society for Testing and Materials, Philadelphia, 1996) p. 825.

[12] H. Ruhmann, R. Manzel, H.-J. Sell and D. Charquet, in: Proc. 11th Int. Symp. on Zirconium in the Nuclear Industry, ASTM-STP 1295 (American Society for Testing and Materials, Philadelphia, 1996) p. 865.

[13] J.-P. Gros and J.-F. Wadier, J. Nucl. Mater. 172 (1990) 85.

[14] F. Garzarolli, H. Stehle, E. Steinberg and H. Weidinger, in: Proc. 7th Int. Symp. on Zirconium in the Nuclear Industry, ASTM-STP 939 (American Society for Testing and Materials, Philadelphia, 1987) p. 417.

[15] H.G. Weidinger, F. Garzarolli, C.M. Euken and E.F. Baroch, in: Proc. 7th Int. Symp. on Zirconium in the Nuclear Industry, ASTM-STP 939 (American Society for Testing and Materials, Philadelphia, 1987) p. 364.

[16] E. Steinberg, H.G. Weidinger and A. Schaa, in: Proc. 6th Int. Symp. on Zirconium in the Nuclear Industry, ASTM-STP 824 (American Society for Testing and Materials, Philadelphia, 1984) p. 106.

[17] B. Cheng and R.B. Adamson, in: Proc. 7th Int. Symp. on Zirconium in the Nuclear Industry, ASTM-STP 939 (American Society for Testing and Materials, Philadelphia, 1987) p. 387.

[18] G. Maussner, E. Steinberg and E. Tenckhoff, in: Proc. 7th Int. Symp. on Zirconium in the Nuclear Industry, ASTM-STP 939 (American Society for Testing and Materials, Philadelphia, 1987) p. 307.

[19] D. Charquet, E. Steinberg and Y. Millet, in Proc. 7th Int. Symp. on Zirconium in the Nuclear Industry, ASTM-STP 939 (American Society for Testing and Materials, Philadelphia, 1987) p. 431.

[20] Y.H. Jeong, K.S. Rheem and H.M. Chung, in: Proc. 9th Int. Symp. on Zirconium in the Nuclear Industry, ASTM-STP 1132 (American Society for Testing and Materials, Philadelphia, 1991) p. 683.

[21] B.J. Herb, J.M. McCarthy, C.T. Wang and H. Ruhmann, in: Proc. 10th Int. Symp. 
on Zirconium in the Nuclear Industry, ASTM-STP 1245 (American Society for Testing and Materials, Philadelphia, 1994) p. 419.

[22] E.R. Bradley, J.H. Schemel and A-L Nystrom, in: Proc. 9th Int. Symp. on Zirconium in the Nuclear Industry, ASTM-STP 1132 (American Society for Testing and Materials, Philadelphia, 1991) p. 304.

[23] K. Ogata, Y. Mishima, T. Okubo, T. Aoki, T. Hattori, T. Fujibayashi, M. Inagaki, K. Murota, T. Kodama and K. Abe, in: Proc. 8th Int. Symp. on Zirconium in the Nuclear Industry, ASTM-STP 1023 (American Society for Testing and Materials, Philadelphia, 1989) p. 291.

[24] P. Rudling and A.J. Machiels in: Proc. 8th Int. Symp. on Zirconium in the Nuclear Industry, ASTM-STP 1023 (American Society for Testing and Materials, Philadelphia, 1989) p. 315.

[25] G. Ostberg, Jernkontorets Annaler. 145 (1961) 119.

[26] A. Miquet, D. Charquet, C. Michaut and C.H. Allibert, J. Nucl. Mater. 105 (1982) 142.

[27] K. Loucif, R. Borrelly and P. Merle, J. Nucl. Mater. 189 (1992) 34.

[28] W.J.S. Yang and R.B. Adamson, in: Proc. 8th Int. Symp. on Zirconium in the Nuclear Industry, ASTM-STP 1023 (American Society for Testing and Materials, Philadelphia, 1989) p. 451.

[29] N.V. Bangaru, R.A. Busch and J.H. Schemel, in: Proc. 7th Int. Symp. on Zirconium in the Nuclear Industry, ASTM-STP 939 (American Society for Testing and Materials, Philadelphia, 1987) p. 341.

[30] D. Charquet and E. Alheritiere, in: Proc. 7th Int. Symp. on Zirconium in the Nuclear Industry, ASTM-STP 939 (American Society for Testing and Materials, Philadelphia, 1987) p. 284.

[31] P. Rudling, K. Lundblad-Vannesjo, G. Vesterlund and A.R. Massih, in Proc. 7th Int. Symp. on Zirconium in the Nuclear Industry, ASTM-STP 939 (American Society for Testing and Materials, Philadelphia, 1987) p. 292.

[32] T. Andersson and T. Thorvaldsson, in: Proc. 7th Int. Symp. on Zirconium in the Nuclear Industry, ASTM-STP 939 (American Society for Testing and Materials, Philadelphia, 1987) p. 321.

[33] D.F. Taylor, Zirconium Alloy Fuel Cladding, U.S. Patent No. 5,436,947 (1995).

[34] C.T. Wang, C.M. Euken and R.A. Graham, in: Proc. 9th Int. Symp. on Zirconium in the Nuclear Industry, ASTM-STP 1132 (American Society for Testing and Materials, Philadelphia, 1991) p. 319.

[35] M. Senna, Bull. Japan Inst. Met. 32 (1993) 32.

[36] D.L. Douglass, The Metallurgy of Zirconium, Atomic Energy Review, Supplement 1971 (International Atomic Energy Agency, Vienna, 1971) p. 140. 


\section{FIGURE CAPTIONS}

Figure 1. Bright-field optical micrograph of W2 cladding after $\beta F$ heat treatment.

Figure 2. Low-magnification bright-field (a) and high-magnification interferencecontrast (b) optical micrographs of W2 cladding after BSF heat treatment. Also typical of BF950SF microstructure.

Figure 3. Transition in slow-cooling sensitization at the $(\alpha+\beta) / \beta$ transus. Steam-test results for W2 cladding after TSF heat treatments. Labeling shows peak temperature $T$.

Figure 4. Critical temperature and $(\alpha+\chi) /(\alpha+\beta+\chi)$ transus. Transitions in slow-cool-andhold sensitization. Steam-test results for $W 2$ cladding after $\beta S-T_{f}(t) F$ heat treatments. Labeling shows final pre-quench temperature $T_{f}$ and hold-time $t$ in hours.

Figure 5. Interference-contrast optical micrograph of W2 cladding after $\beta S-834(18) \mathrm{F}$ heat treatment. Also typical of any $\beta S-T(t) F$ microstructure where fan-cooling preceded the $(\alpha+\beta+\chi) /(\alpha+\chi)$ transformation.

Figure 6. Transus- and critical-temperature estimates from transition temperatures in Figure 4.

Figure 7. Isothermal sensitization of W2 cladding close to susceptibility. Steam-test results after $18 \mathrm{hr}$ at temperature T. Preparatory $\beta S-826(2) \mathrm{F}$ (upper row) or $B S-829(2) \mathrm{F}$ (lower row) heat treatment. Labeling shows isothermal annealing temperature $\mathrm{T}$.

Figure 8. Isothermal sensitization of $\mathrm{W} 2$ cladding. Steam-test results after $T(t) F$ heat treatment. Labeling shows annealing time $t$ at temperature $T$.

Figure 9. Isothermal sensitization at $835^{\circ} \mathrm{C}$. Steam-test results for Western Zirconium and Teledyne Wah Chang Zircaloy-2 in several formats: W2 cladding, ZNR plate with nitrogen additions, commercial rod and plate, T22 ingot. Labeling shows nitrogen content and annealing time.

Figure 10. Isothermal healing of highly-susceptible W2 cladding. Steam-test results after $\beta S F T(t) F$ heat treatment. Labeling shows annealing time $t$ at temperature $T\left({ }^{\circ} \mathrm{C}\right)$.

Figure 11. $(\alpha+\beta+\chi) /(\alpha+\beta)$ transus. Transition in protection against slow-cooling sensitization. Steam-test results for $\mathrm{W} 2$ cladding after $\beta F T(t) 950$ SF heat treatments. Labeling shows time $t$ at recrystallizing temperature $T$.

Figure 12. Bright-field optical micrograph of W2 cladding after BF790(3)950SF heat treatment. 
Figure 13. Interference-contrast optical micrograph of W2 cladding after $800(3) B S F$ heat treatment.

Figure 14. Interference-contrast optical micrograph of W2 cladding after $\beta S F 950 \mathrm{~F}$ heat treatment.

Figure 15. Interference-contrast optical micrograph of W2 cladding after 950(2)SF950F heat treatment. Also typical of 950(2)F microstructure.

Figure 16. Effect of initial time at $1010^{\circ} \mathrm{C}$ in $\beta$ phase field on slow-cooling sensitization. Steam-test results for initial condition (first row), and after $\beta(t) S F$ heat treatments, for Western Zirconium and Teledyne Wah Chang Zircaloy-2 in several formats: W2 cladding; plate from the re-melt of commercial end-plug rod; ZNR ingot, derivative plate, and derivative plate with nitrogen addition; T2 and T1 cladding; T22 ingot and derivative plate. Labeling shows pre-cooling hold-time $t$ in minutes.

Figure 17. Low-magnification polarized-light (a) and high-magnification bright-field (b) optical micrographs of W2 cladding after $800(3) 840(1.5) F$ heat treatment.

Figure 18. Solute model of Zircaloy nodular corrosion. The $C$ vs. mean-precipitate-size curve corresponds to steady-state Ostwald ripening at temperature $T<T_{\alpha}$ in the $(\alpha+\chi)$ phase field. Immunity is metastable, and occurs either with very small precipitates or presteady state when $\mathrm{C}_{\text {mean }}>\mathrm{C}_{\mathrm{c}}$. The trajectory arrows denote steady-state ripening in a susceptible material. 


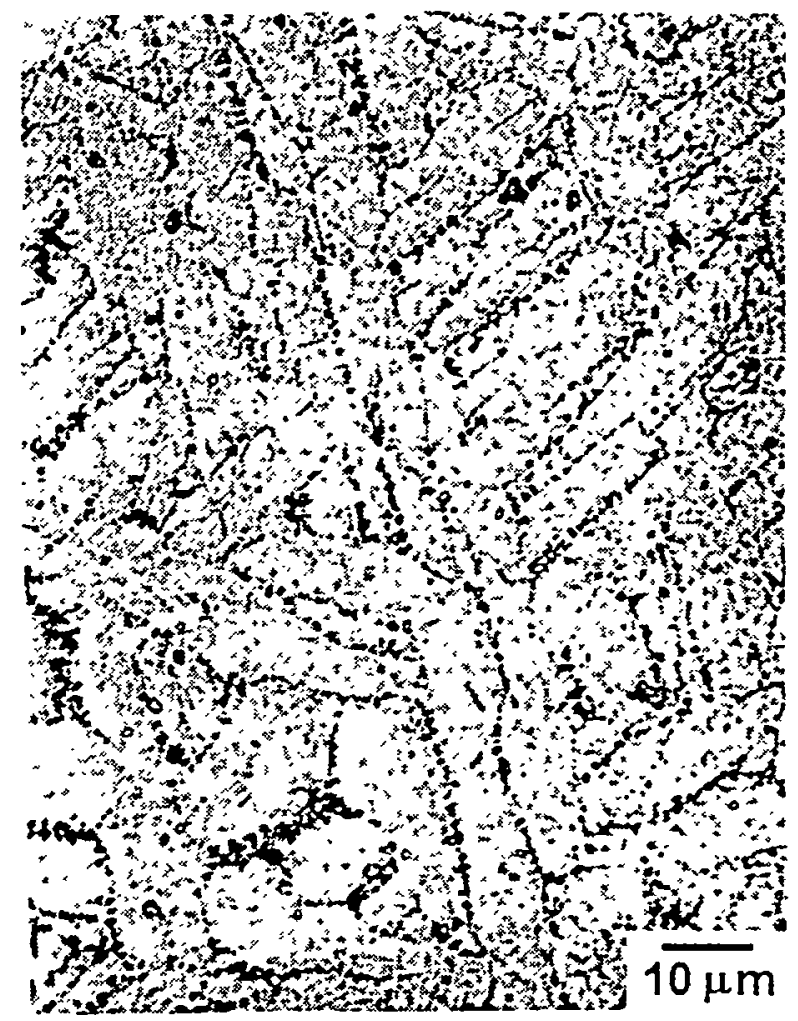

Figure 1. Bright-field optical micrograph of $\mathrm{W} 2$ cladding after $\beta \mathrm{F}$ heat treatment. 

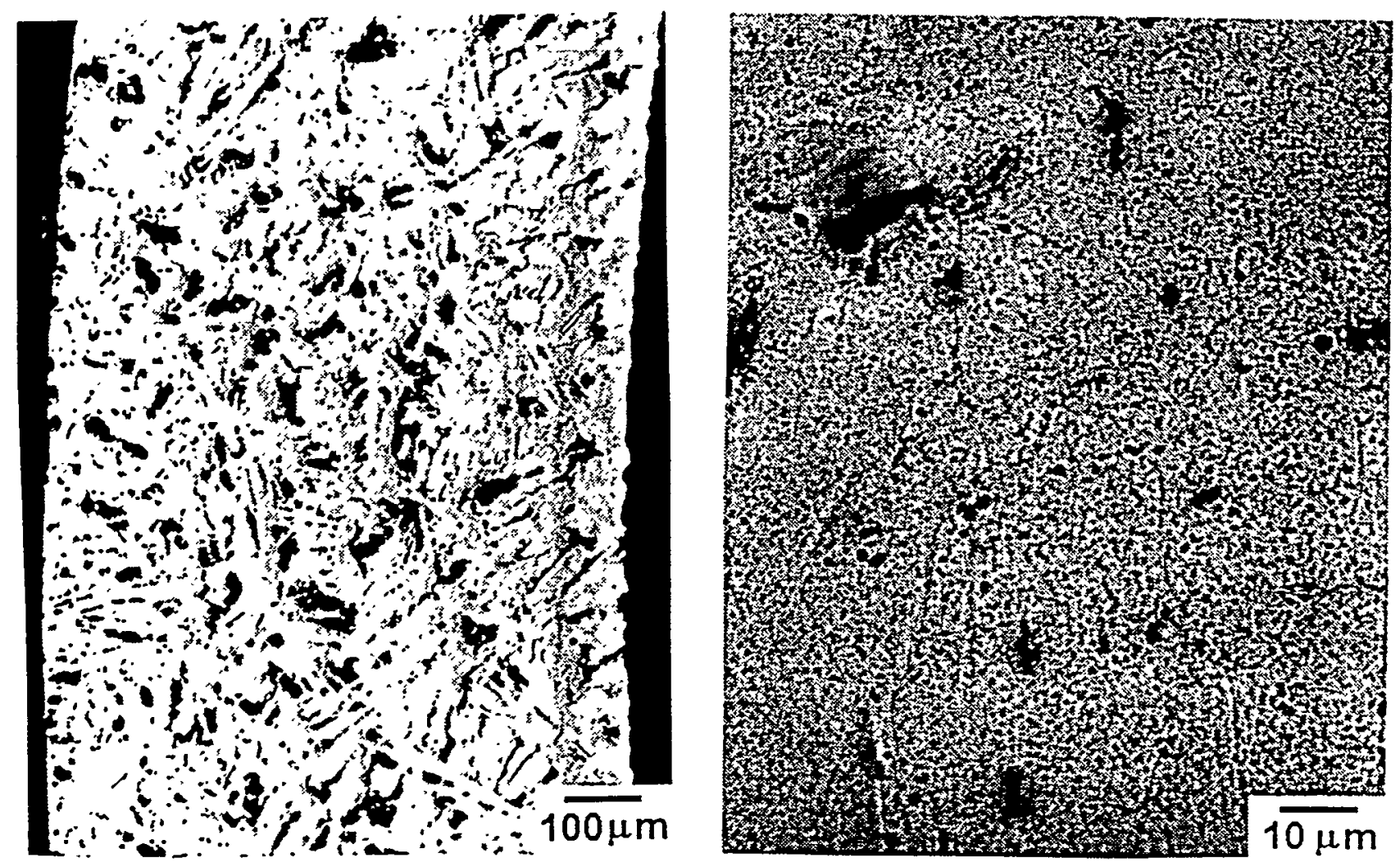

Figure 2. Low-magnification bright-field (a) and high-magnification interferencecontrast (b) optical micrographs of W2 cladding after $\beta S F$ heat treatment. Also typical of BF950SF microstructure. 


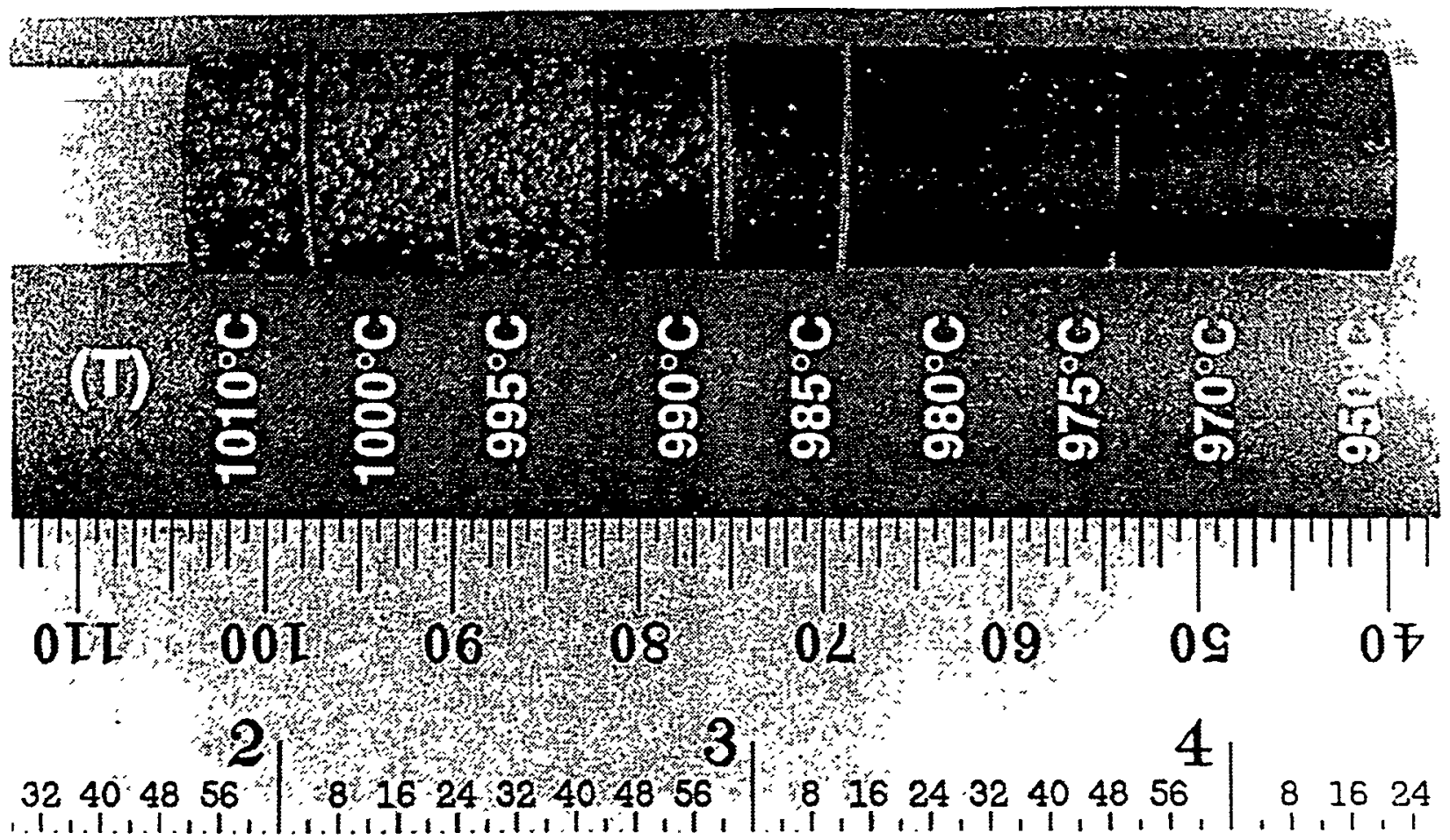

Figure 3. Transition in slow-cooling sensitization at the $(\alpha+\beta) / \beta$ transus. Steam-test results for W2 cladding after TSF heat treatments. Labeling shows peak temperature $T$. 


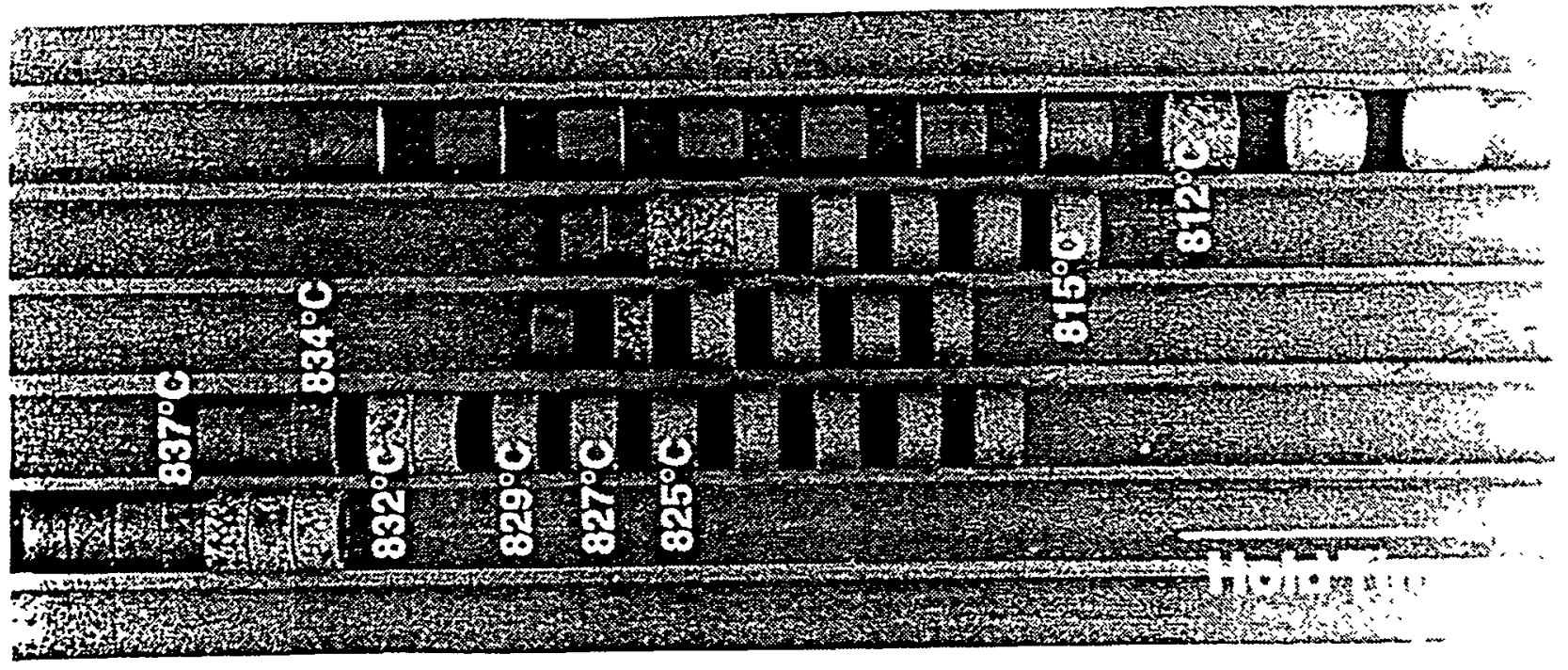

Figure 4. Critical temperature and $(\alpha+\chi) /(\alpha+\beta+\chi)$ transus. Transitions in slow-cooland-hold sensitization. Steam-test results for W2 cladding after $\beta S-T_{r}(t) F$ heat treatments. Labeling shows final pre-quench temperature $T_{f}$ and hold-time $t$ in hours. 


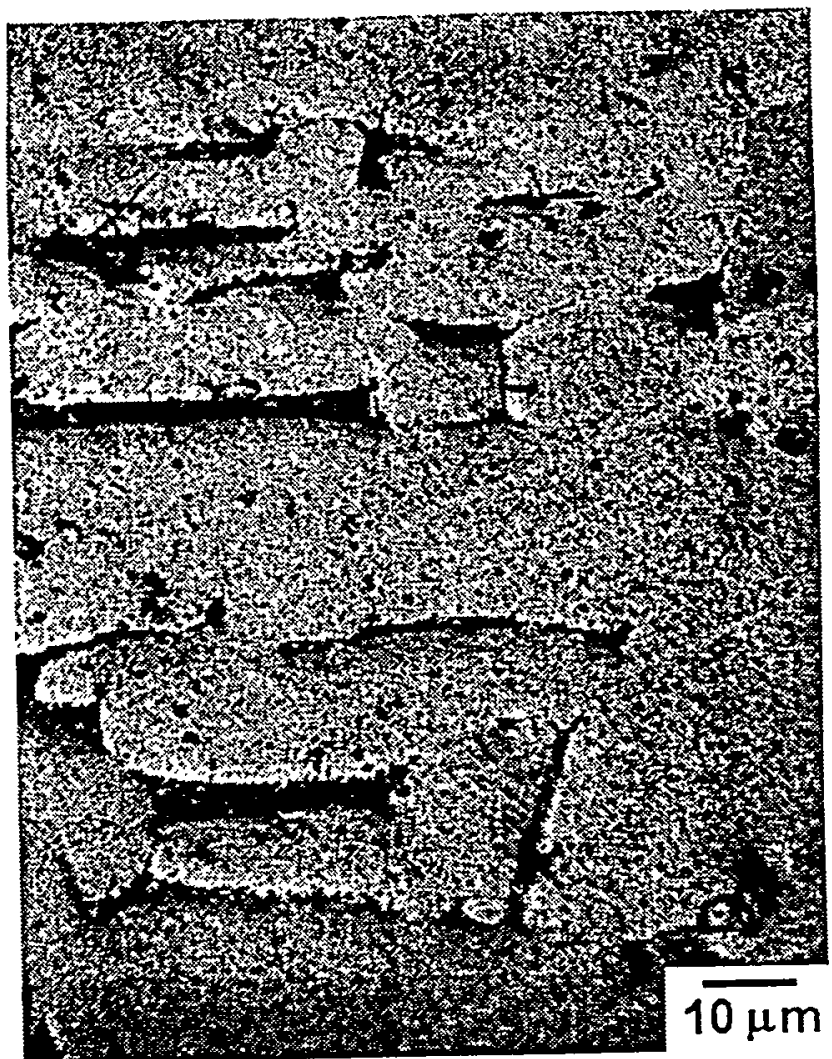

Figure 5. Interference-contrast optical micrograph of W2 cladding after $\beta S-834(18) \mathrm{F}$ heat treatment. Also typical of any $\beta S-T(t) F$ microstructure where fan-cooling preceded the $(\alpha+\beta+\chi) /(\alpha+\chi)$ transformation. 


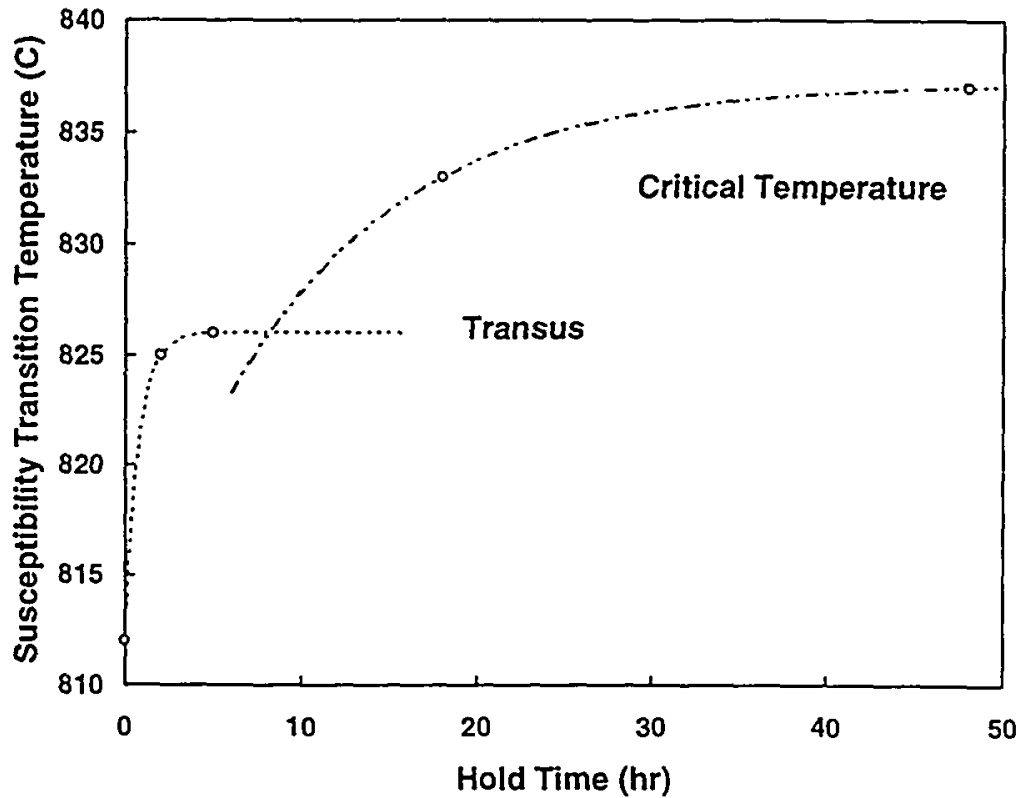

Figure 6. Transus- and critical-temperature estimates from transition temperatures in Figure 4. 


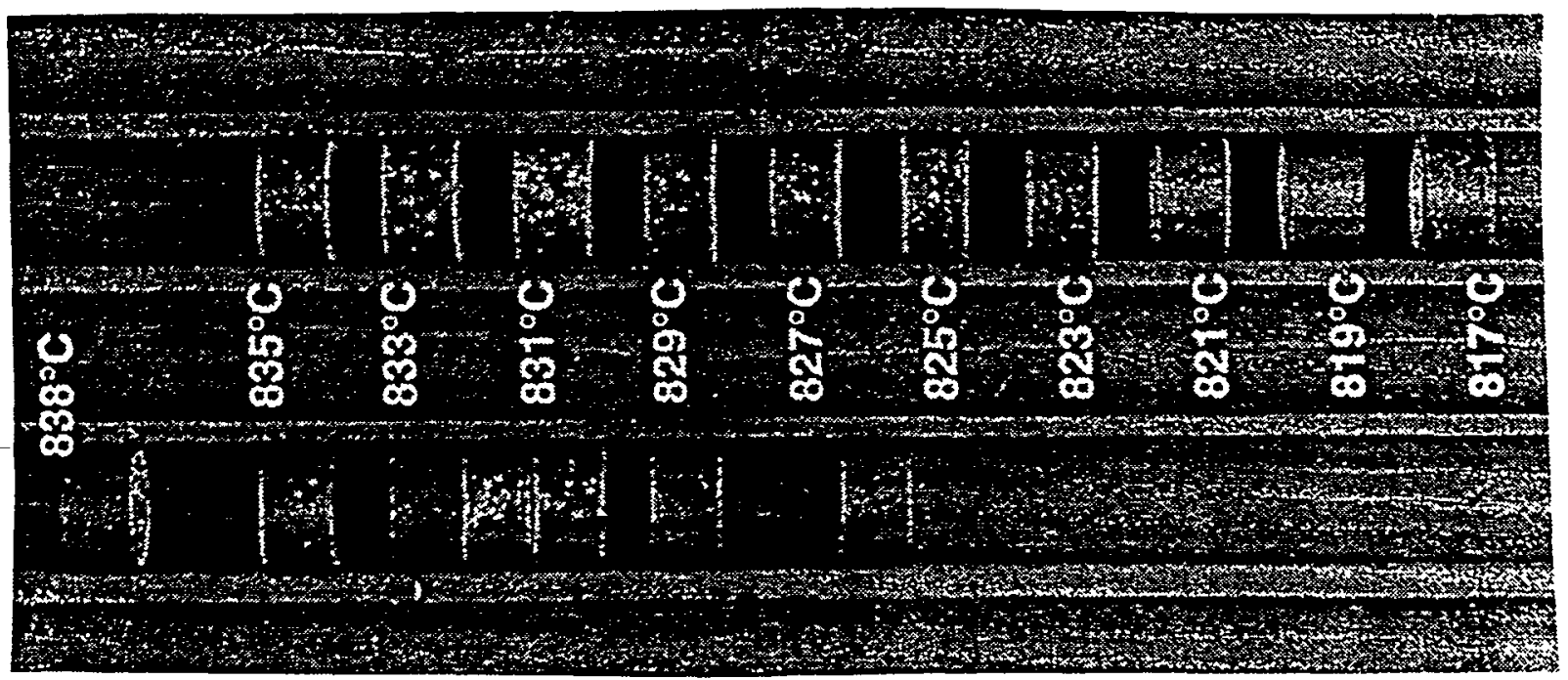

Figure 7. Isothermal sensitization of W2 cladding close to susceptibility. Steam-test results after $18 \mathrm{hr}$ at temperature $T$. Preparatory $\beta S-826(2) \mathrm{F}$ (upper row) or $\beta S-829(2) \mathrm{F}$ (lower row) heat treatment. Labeling shows isothermal annealing temperature $\mathrm{T}$. 


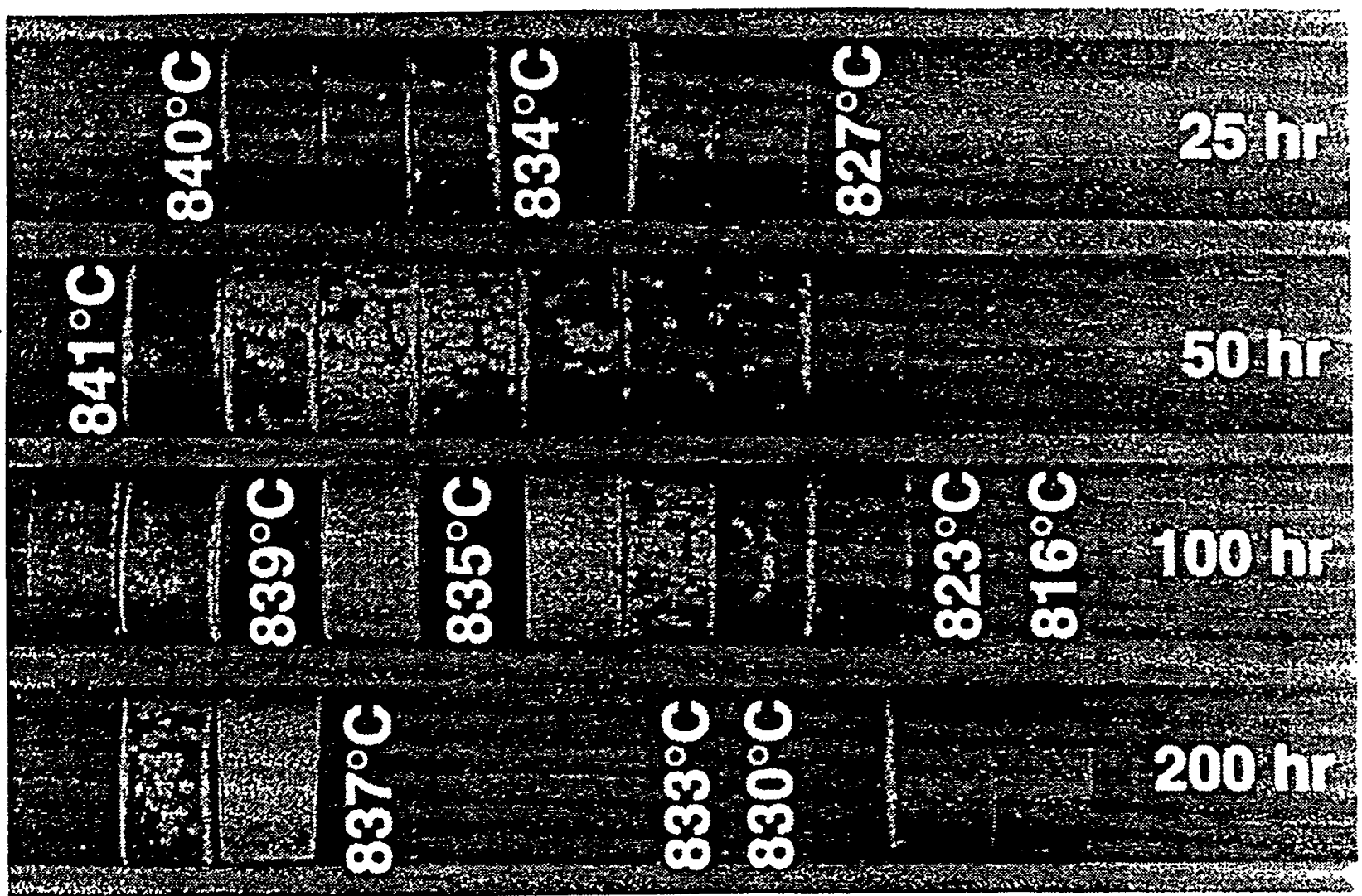

Figure 8. Isothermal sensitization of $\mathrm{W} 2$ cladding. Steam-test results after $T(t) F$ heat treatment. Labeling shows annealing time $t$ at temperature $T$. 


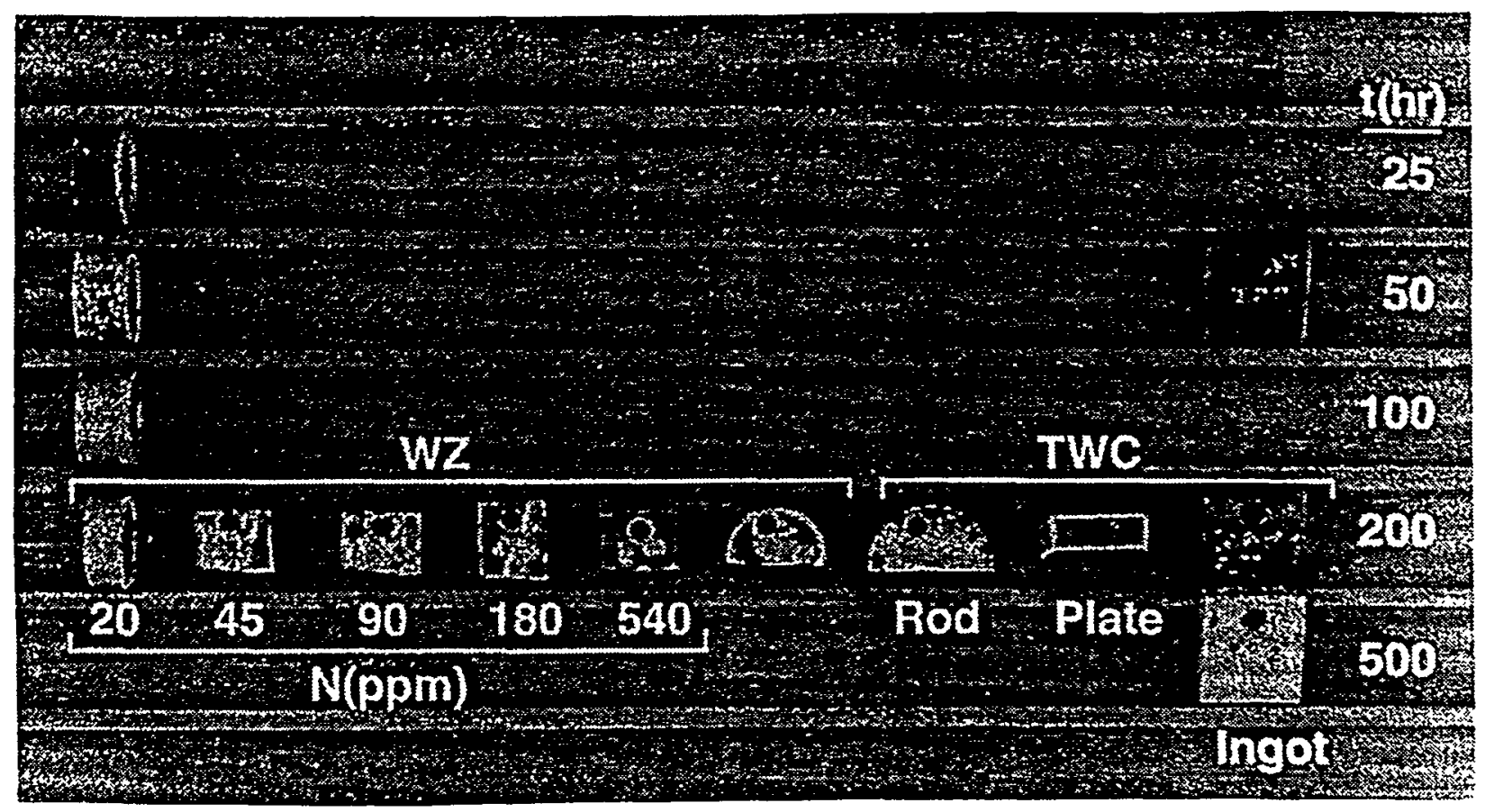

Figure 9. Isothermal sensitization at $835^{\circ} \mathrm{C}$. Steam-test results for Western Zirconium and Teledyne Wah Chang Zircaloy-2 in several formats: W2 cladding, ZNR plate with nitrogen additions, commercial rod and plate, T22 ingot. Labeling shows nitrogen content and annealing time. 


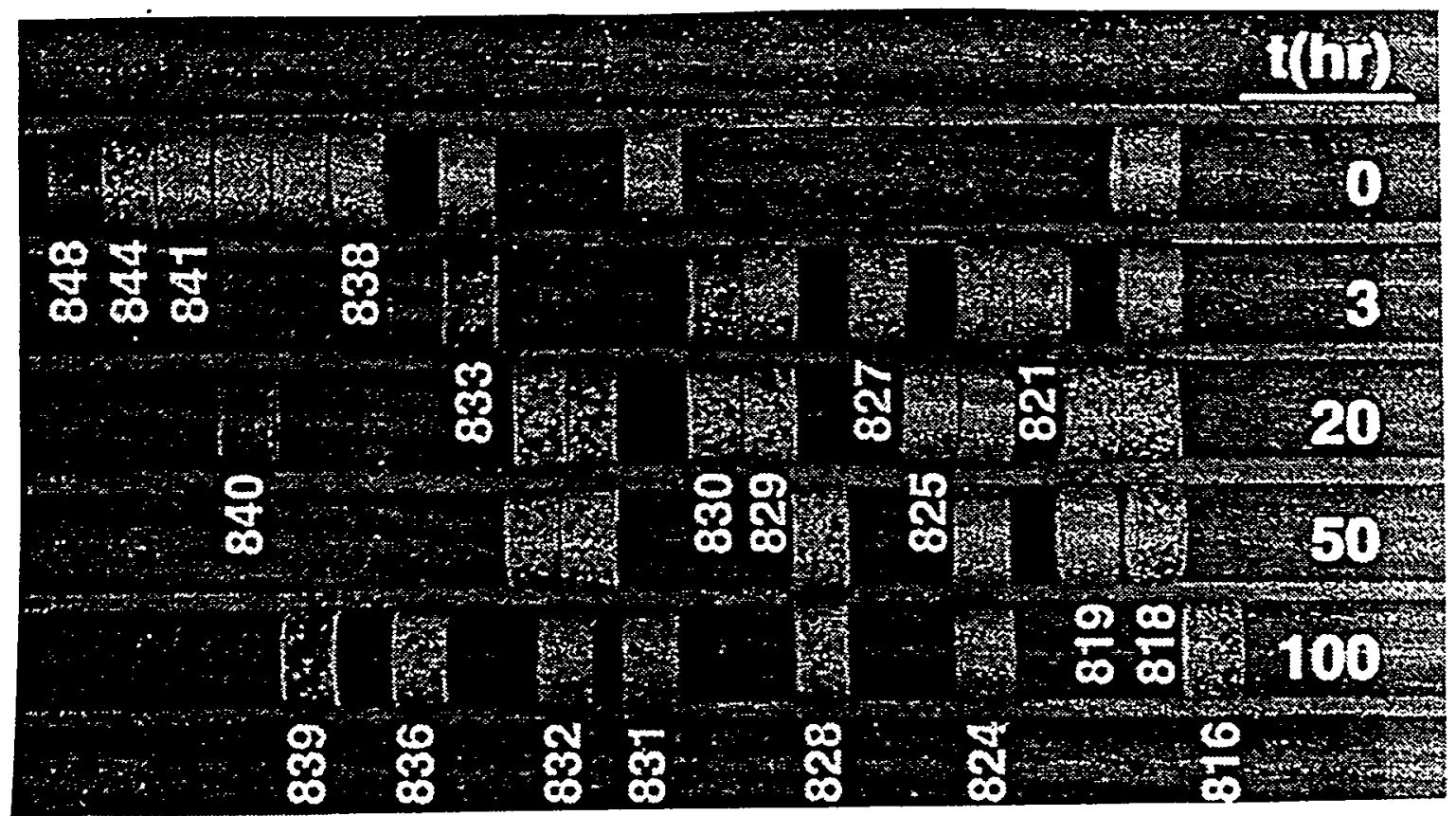

Figure 10. Isothermal healing of highly-susceptible W2 cladding. Steam-test results after $\beta S F T(t) F$ heat treatment. Labeling shows annealing time $t$ at temperature $\mathrm{T}\left({ }^{\circ} \mathrm{C}\right)$. 


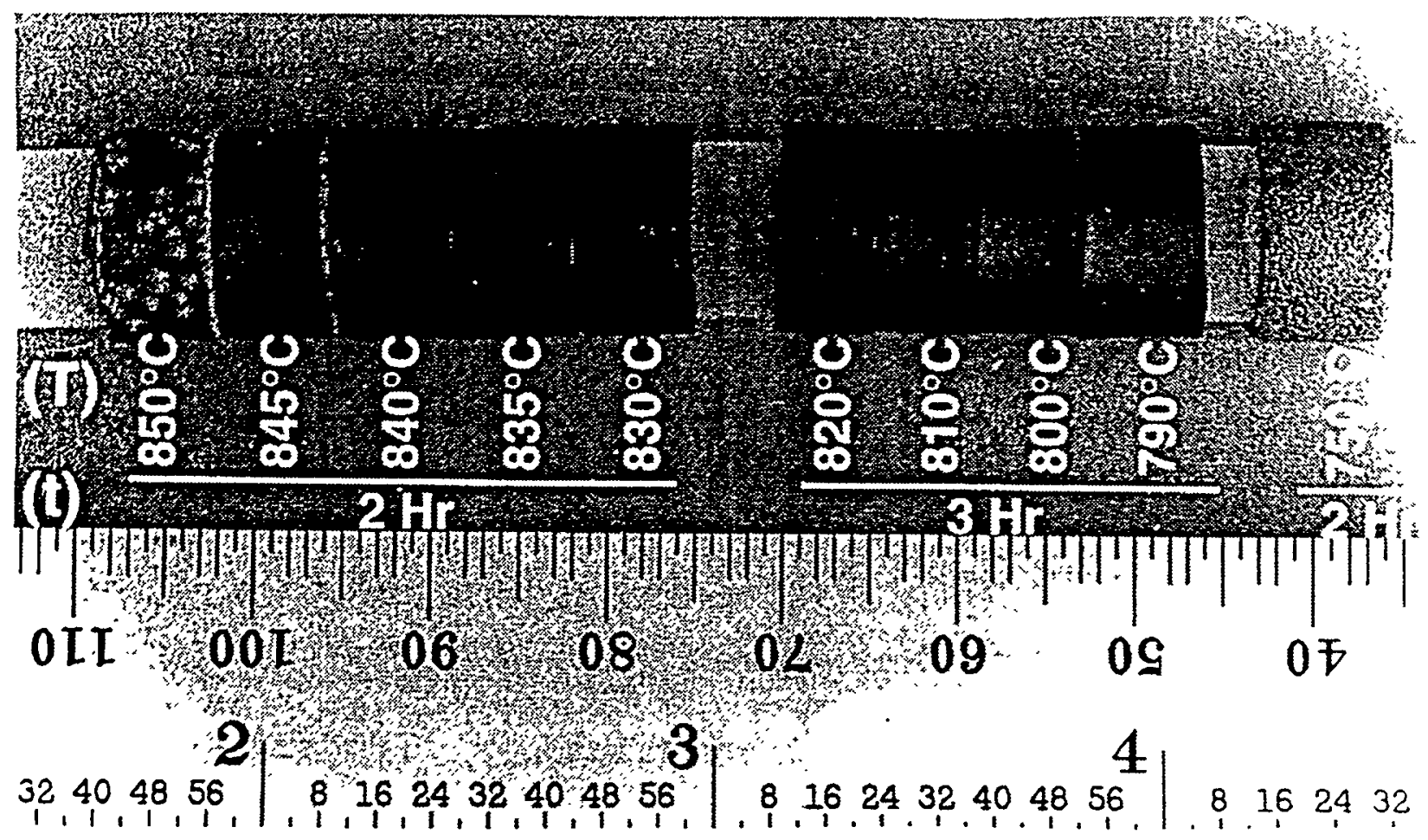

Figure 11. $(\alpha+\beta+\chi) /(\alpha+\beta)$ transus. Transition in protection against slow-cooling sensitization. Steam-test results for W2 cladding after $\beta F T(t) 950$ SF heat treatments. Labeling shows time $t$ at recrystallizing temperature $\mathrm{T}$. 


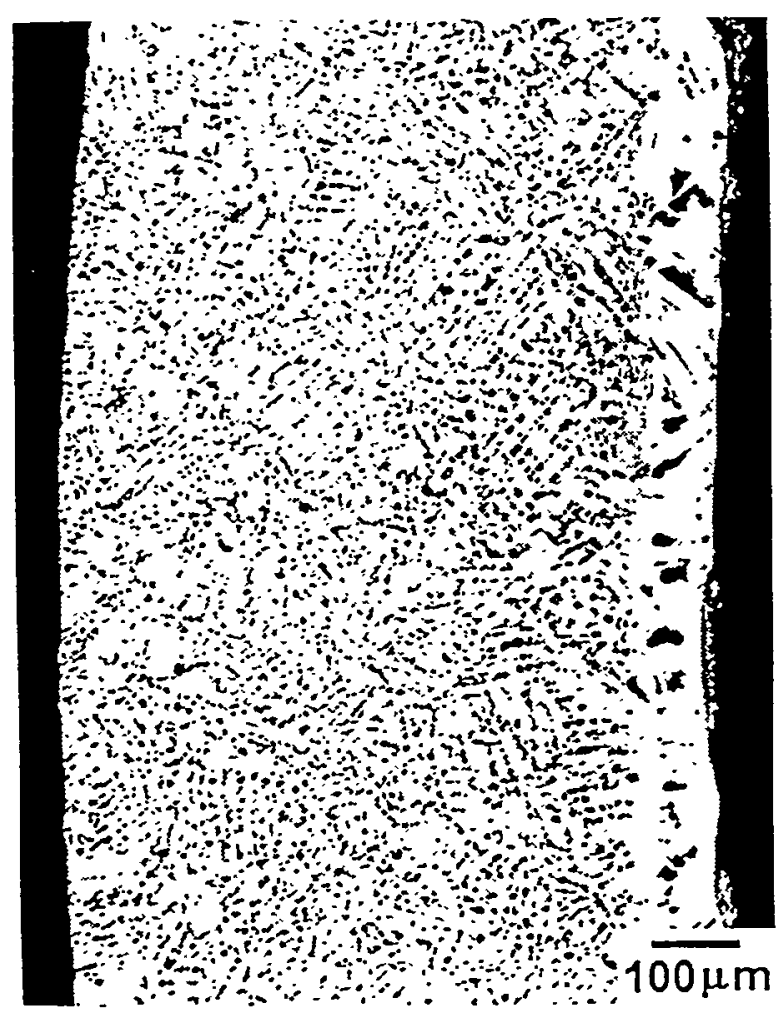

Figure 12. Bright-field optical micrograph of W2 cladding after $\beta F 790(3) 950 S F$ heat treatment. 


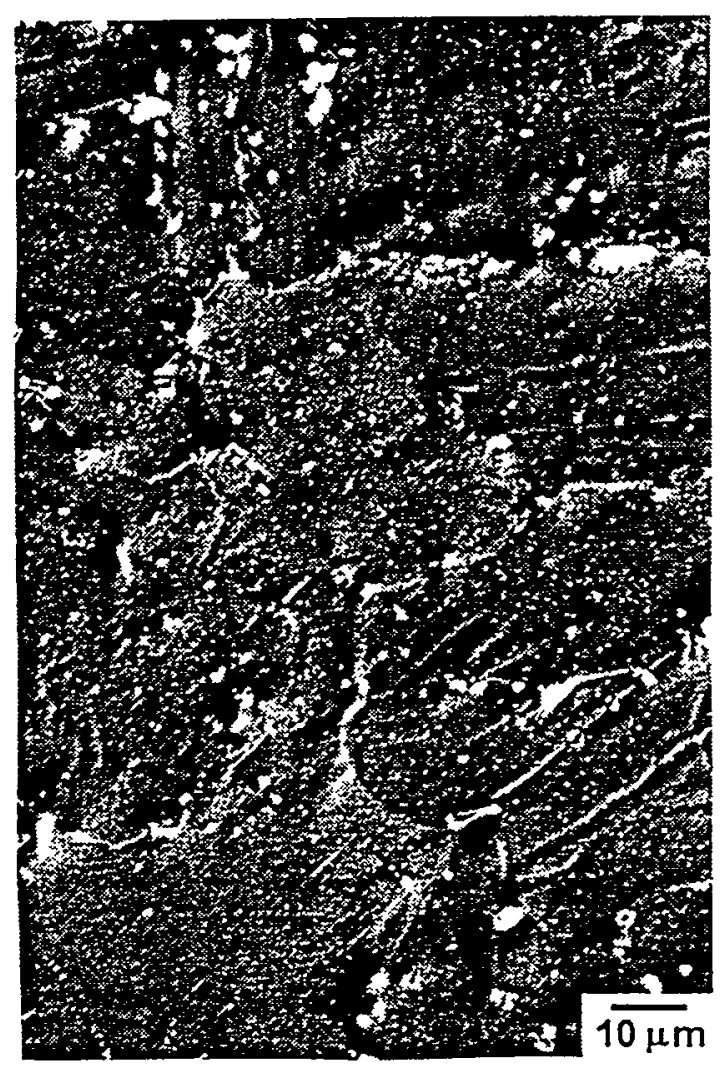

Figure 13. Interference-contrast optical micrograph of W2 cladding after 800(3)ßSF heat treatment. 


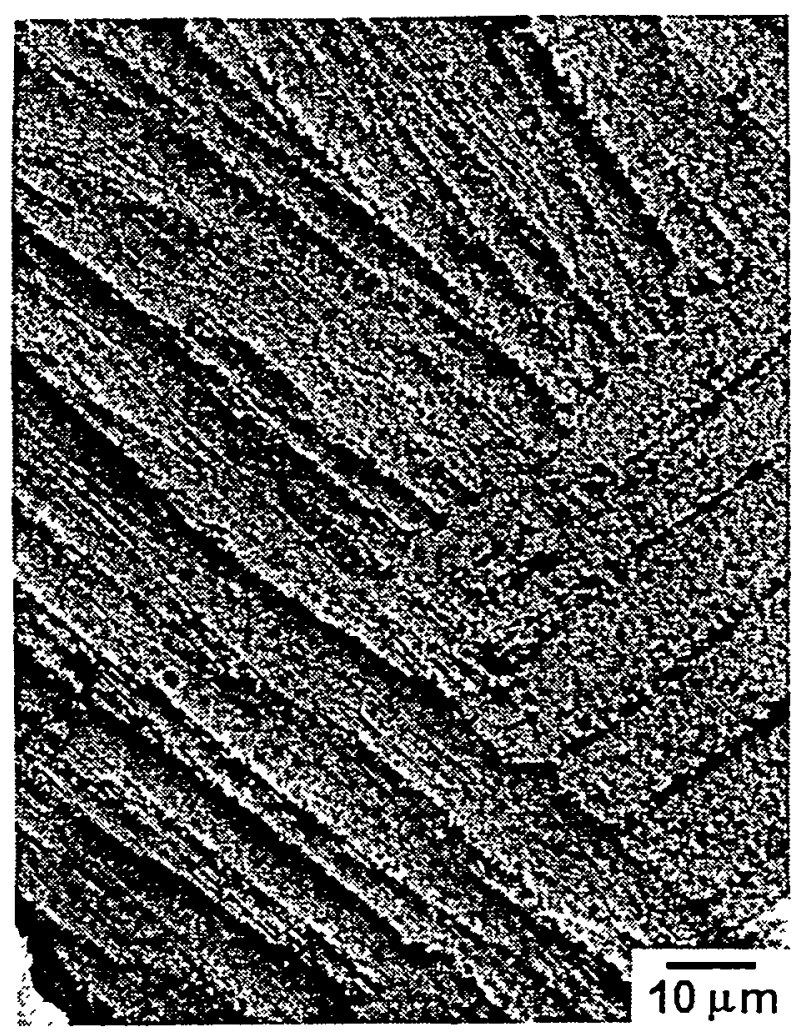

Figure 14. Interference-contrast optical micrograph of W2 cladding after $\beta S F 950 \mathrm{~F}$ heat treatment. 
REPRODUCED AT GOVT EXPENSE \#.4

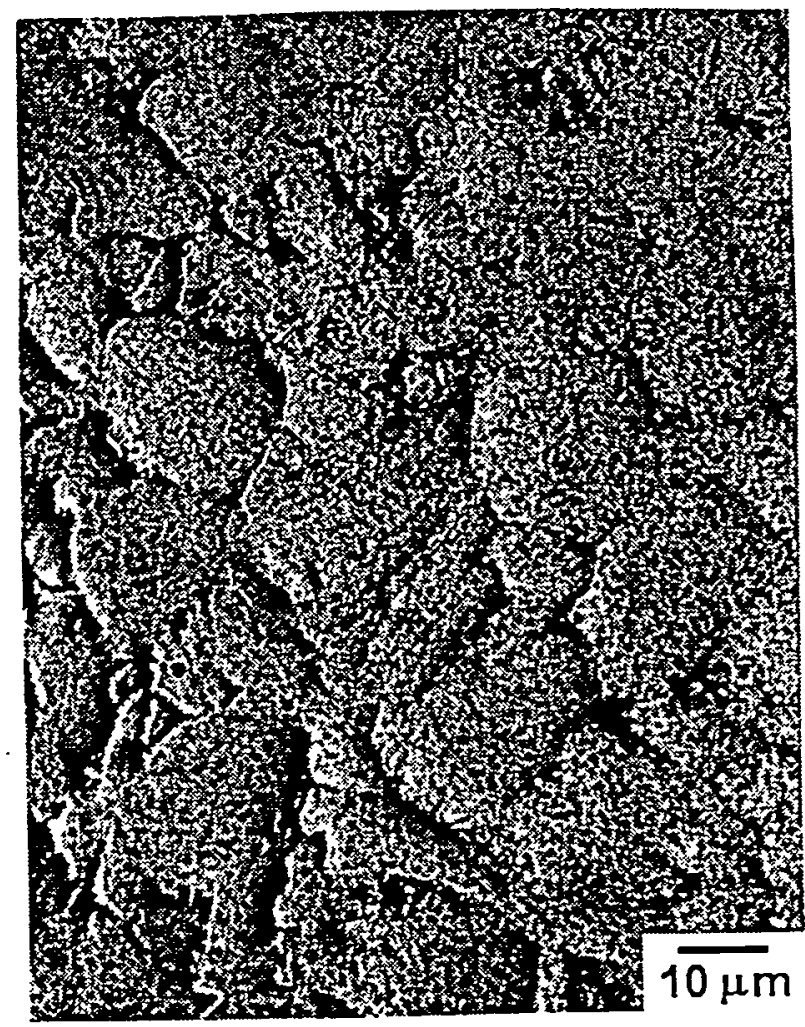

Figure 15. Interference-contrast optical micrograph of W2 cladding after $950(2) \mathrm{SF} 950 \mathrm{~F}$ heat treatment. Also typical of 950(2)F microstructure. 


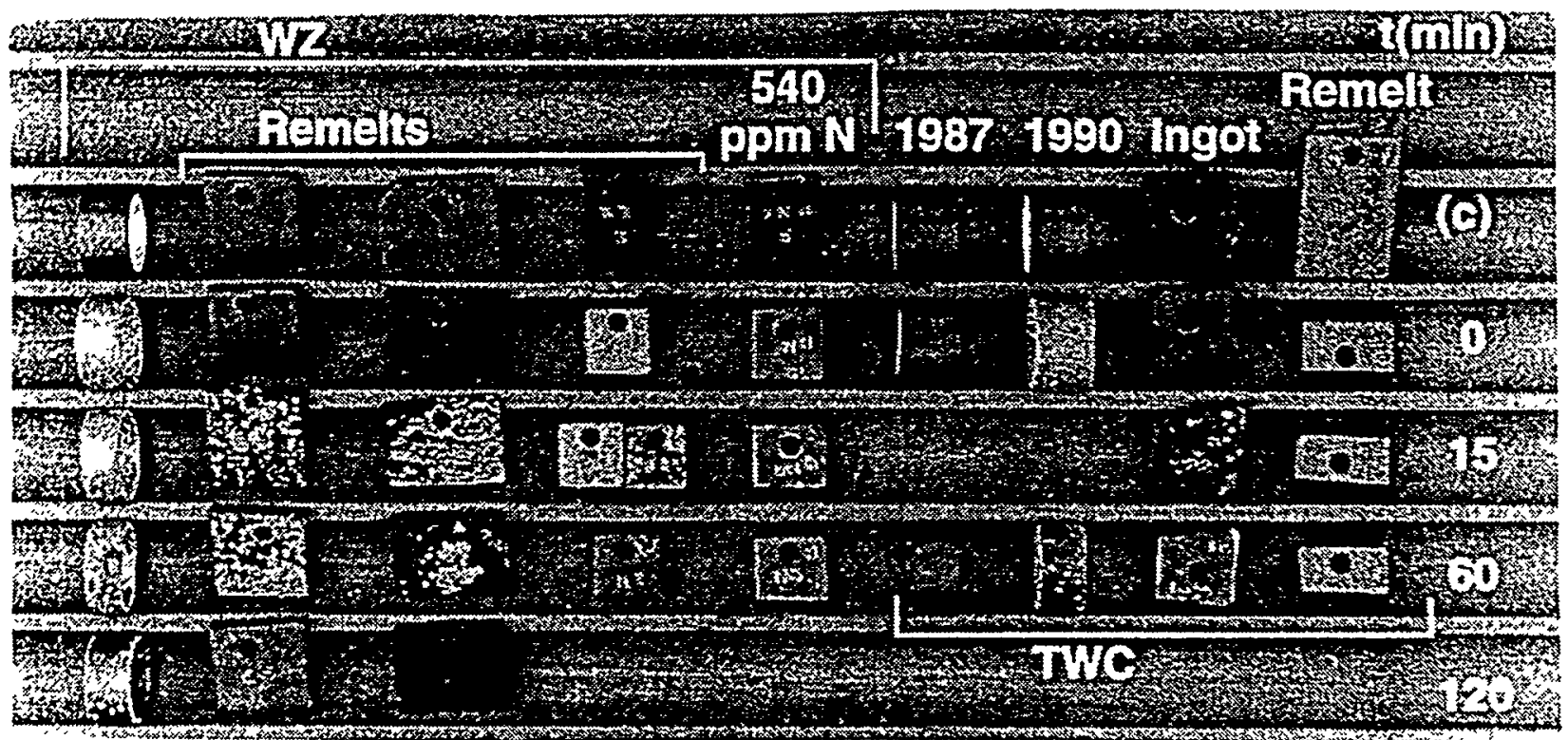

Figure 16. Effect of initial time at $1010^{\circ} \mathrm{C}$ in $\beta$ phase field on slow-cooling sensitization. Steam-test results for initial condition (first row), and after $\beta(t) S F$ heat treatments, for Western Zirconium and Teledyne Wah Chang Zircaloy-2 in several formats: W2 cladding; plate from the re-melt of commercial end-plug rod; ZNR ingot, derivative plate, and derivative plate with nitrogen addition; T2 and T1 cladding; T22 ingot and derivative plate. Labeling shows pre-cooling hold-time $t$ in minutes. 

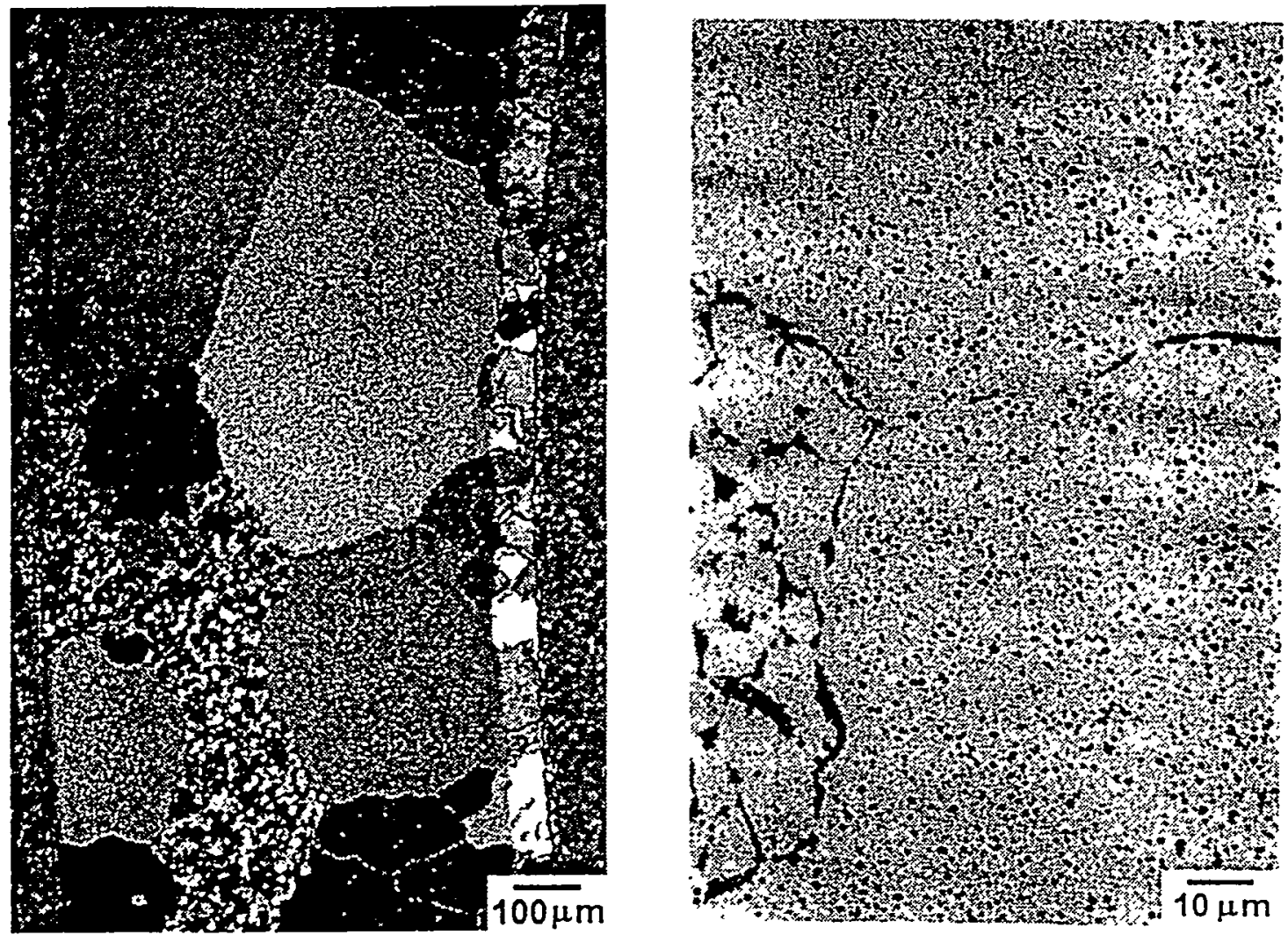

Figure 17. Low-magnification polarized-light (a) and high-magnification bright-field (b) optical micrographs of W2 cladding after $800(3) 840(1.5) \mathrm{F}$ heat treatment. 


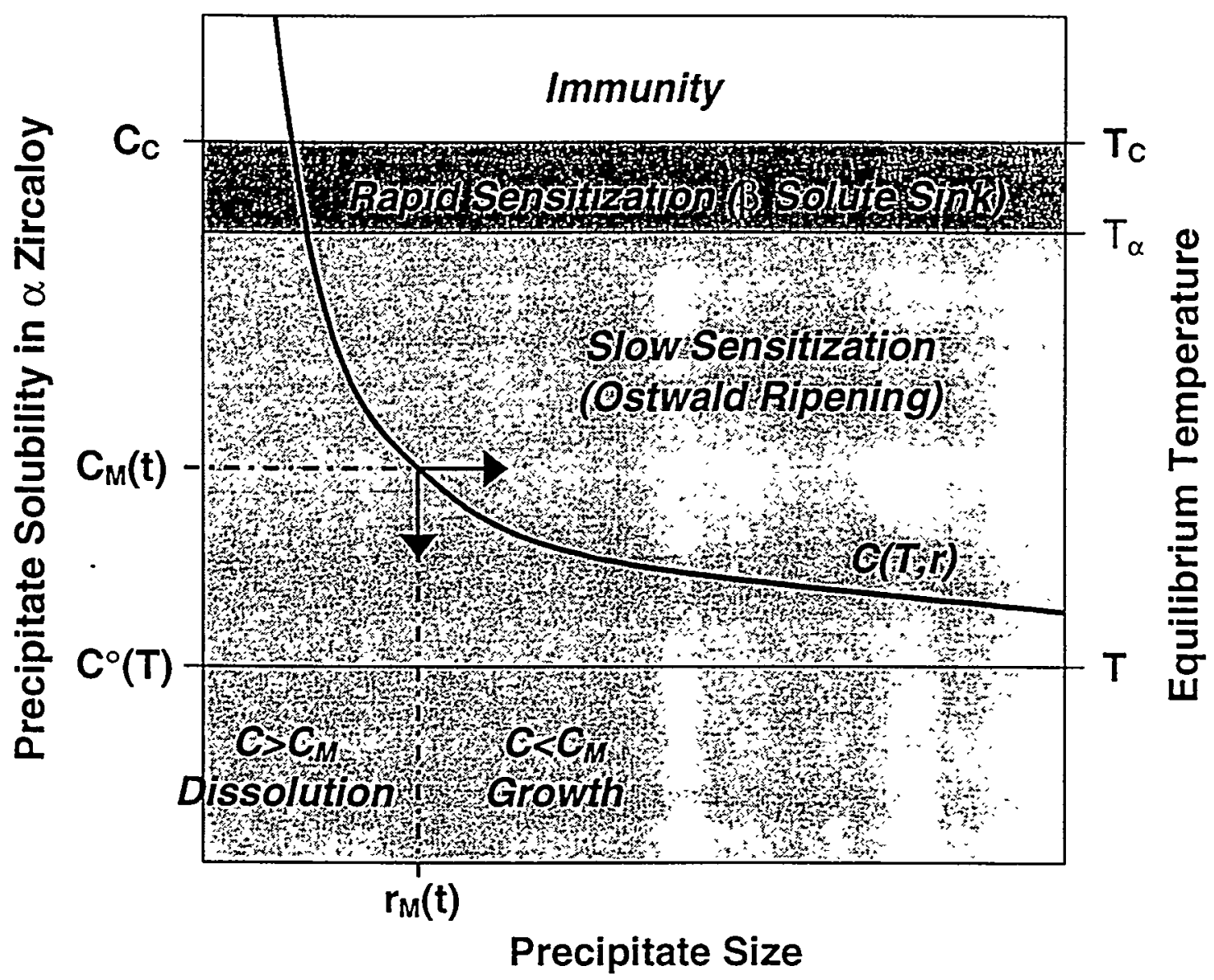

Figure 18. Solute model of Zircaloy nodular corrosion. The $C$ vs. mean-precipitate-size curve corresponds to steady-state Ostwald ripening at temperature $T<T_{\alpha}$ in the $(\alpha+\chi)$ phase field. Immunity is metastable, and occurs either with very small precipitates or presteady state when $\mathrm{C}_{\text {mean }}>\mathrm{C}_{\mathrm{c}}$. The trajectory arrows denote steady-state ripening in a susceptible material. 